\title{
Experimental Review of the Homogeneous Temperature Assumption in Post-Flashover Compartment Fires
}

\author{
Jamie Stern-Gottfried ${ }^{1,2}$, Guillermo Rein ${ }^{1, *}$, Luke A. Bisby ${ }^{1}$, and Jose L. Torero ${ }^{1}$ \\ 1: BRE Centre for Fire Safety Engineering, University of Edinburgh, EH9 3JL, UK \\ 2: Arup Fire, London, W1T 4BQ, UK \\ *Corresponding author at: BRE Centre for Fire Safety Engineering, University of \\ Edinburgh, EH9 3JL, UK \\ Tel.: $+44(0) 1316507214$ \\ Fax: $+44(0) 1316506554$ \\ E-mail address: G.Rein@ed.ac.uk
}

\begin{abstract}
Traditional methods for quantifying and modelling compartment fires for structural engineering analysis assume spatially homogeneous temperature conditions. The accuracy and range of validity of this assumption is examined here using the previously conducted fire tests of Cardington (1999) and Dalmarnock (2006). Statistical analyses of the test measurements provide insights into the temperature field in the compartments. The temperature distributions are statistically examined in terms of dispersion from the spatial compartment average. The results clearly show that uniform temperature conditions are not present and variation from the compartment average exists. Peak local temperatures range from $23 \%$ to $75 \%$ higher than the compartment average, with a mean peak increase of $38 \%$. Local minimum temperatures range from $29 \%$ to $99 \%$ below the spatial average, with a mean local minimum temperature of $49 \%$. The experimental data are then applied to typical structural elements as a case study to examine the potential impact of the gas temperature dispersion above the compartment average on the element heating. Compared to calculations using the compartment average, this analysis results in increased element temperature rises of up to $25 \%$ and reductions of the time to attain a pre-defined critical temperature of up to $31 \%$ for the $80^{\text {th }}$ percentile temperature increase. The results show that the homogeneous temperature assumption does not hold well in post-flashover compartment fires. Instead, a rational statistical approach to fire behaviour could be used in fire safety and structural engineering applications.
\end{abstract}

Keywords: homogeneity, enclosure fire, uniform conditions, well stirred reactor, structure, Dalmarnock, Cardington.

\section{INTRODUCTION}

Post-flashover compartment fires are of particular relevance to the analysis of structural fire performance because of their high severity. Traditional methods for quantifying and modelling post-flashover fires for structural engineering analysis assume homogeneous temperature conditions, i.e. the gas phase temperature distribution is taken to be spatially uniform and does not have considerable gradients. For example, the methodologies for structural fire analysis that use the standard and parametric temperature-time curves assume this uniform temperature regardless of the 
compartment size or fire power. This assumption has been necessary to develop simple analytical solutions to the temperature evolution and further the understanding of postflashover compartment fires and subsequent structural responses [1].

However, the accuracy and range of validity of the homogeneous temperature assumption has not been thoroughly examined before. This is generally due to the limited number of post-flashover fire experiments available and especially to the low spatial resolution of temperature measurements used in such tests.

This paper reviews the validity of this assumption using previously conducted fire tests. The tests chosen for these analyses are the Cardington (1999) and Dalmarnock (2006) tests. The choices are based on the detailed instrumentation and the large geometry of the tests. The paper also examines the impact of the departure from the homogeneous temperature assumption on typical thermal analyses that represent the basis behind structural fire calculations. The consequences of these differences on structural behaviour are beyond the scope of this work and thus are not discussed.

\section{THE HOMOGENEOUS TEMPERATURE ASSUMPTION}

\subsection{Origins of the Assumption}

Most theoretical models for quantifying the temperature evolution in postflashover fires are based on the assumption of uniform compartment temperatures [2], which is also referred to as the well stirred reactor assumption. This is the case for both analytical models and zone models. Karlsson and Quintiere [1] note that this assumption, among others, is required for an analytical solution of the energy balance for the compartment. In particular they note that the methods of Magnusson and Thelanderson in 1970 [3] and Babrauskas and Williamson in 1978 [4] adopted this approach. The former is the basis for the Eurocode parametric temperature time curve [1]. Drysdale [5] notes that a justification of this assumption often used is that there is supposedly a small gradient in the vertical temperature distribution during a postflashover fire and even smaller horizontal gradients. For example, a single test from 1975 is cited showing a nearly uniform vertical temperature distribution at one moment at the onset of flashover [5]. However, this justification has not been evaluated any further. Furthermore, due to the limited number of thermocouple trees in most fire tests (typically one or two), the presence of horizontal gradients cannot be investigated and is rarely reported.

Franssen proposed modifications to the Eurocode parametric temperature-time curve to better correlate the predicted peak temperatures with those from 48 experiments [6]. However, dispersions of the temperature data about the compartment averages for the experiments are not given, presumably because the assumption of temperature uniformity was automatically invoked.

The uniform temperature assumption is fundamentally inherent in the test methods used for classifying structural fire resistance. The fire rating system adopted by most building codes and standards worldwide is based on single elements of construction being subjected to furnace tests in which the gas temperature evolution follows that of a uniform standard fire. It is a key aim of these tests to produce as 
uniform a temperature field as possible throughout the furnace. Typical furnace tests include about four to nine thermocouple or plate thermometer measurements in different locations. ISO 834 [7] specifies the compartment temperature as the spatial average from all of the thermocouples monitoring the gas phase. The test requires that each individual thermocouple be within $100^{\circ} \mathrm{C}$ of the standard fire temperature-time curve specified at all times after the initial $10 \mathrm{~min}$. The test also requires that the percentage difference between the areas under the measured compartment average and the standard temperature-time curves be within $15 \%$ of each other after the first $10 \mathrm{~min}, 10 \%$ after $30 \mathrm{~min}, 5 \%$ after $60 \mathrm{~min}$, and 2.5\% thereafter. BS 476: Part 20 [8] and ASTM E119 [9] have similar tolerances.

The tight tolerances required in standard fire tests are specifically set to ensure that the temperature field in the compartment is uniform. While standard fire curves have been criticised before on many counts for not representing natural fires $[5,6,10]$, the spatially homogenous temperature assumption has not typically been one of them.

\subsection{Critiques of the Assumption}

Harmathy [11] presents a qualitative critique of the homogenous temperature assumption, also referred to as the well stirred reactor assumption. The critique states that external flaming close to a vent invalidates the well stirred reactor model. Harmathy suggests division of the compartment into three zones to allow mathematical treatment: a zone of primarily fresh incoming air, a zone dominated by the presence of the flame, and a zone behind the flame with mixed pyrolyzates and combustion products. According to this classification, the homogenous temperature distribution would only be valid in this last zone. However, this critique does not provide any quantification of the non-homogeneity or its effects.

Bøhm and Hadvig [12] reported differences in experimental temperature measurements of $200^{\circ} \mathrm{C}$ to $500^{\circ} \mathrm{C}$ within a single post-flashover fire, with the hottest temperatures in the centre of the compartment. Their test compartment was $4.6 \mathrm{~m} \mathrm{x}$ $4.6 \mathrm{~m} \times 2.5 \mathrm{~m}$, and temperature measurements were made at eight different locations. The temperature differences led to difficulties in predicting the heat fluxes to both the fuel surface and the exposed structure, but no further analysis was made of the effect of the non-uniformity.

Welch et al [13] and Abecassis et al [14] reviewed the experimental data of the Cardington Tests and the Dalmarnock Fire Tests, respectively, in terms of temperature and heat flux fields and concluded they did not support the conventional assumption of uniformity. These tests are described in Section 3.3.

\section{EXPERIMENTAL REVIEW}

The presence of considerable temperature gradients during post-flashover fires has previously been observed, although not systematically examined. Tests in large or irregularly shaped compartments and real fires can provide insight into the potential dispersion of temperatures and are reviewed here. 


\subsection{Non-Uniform Burning in Experiments}

Kirby et al. [15] ran a test series burning wood cribs in a long enclosure with approximate dimensions of $22.9 \mathrm{~m}$ long x $5.6 \mathrm{~m}$ wide $\times 2.8 \mathrm{~m}$ high. All of the tests were ignited at the rear, except one in which all wood cribs were ignited simultaneously. The results of all tests show that the fire moved relatively quickly from the ignition location to the front of the compartment, where the vent was located. After the fuel in the front of the compartment burned out, the fire progressively travelled back into the compartment and ultimately consumed all the fuel and self-extinguished at the rear. Temperature results of Test 1 from this test series are shown below in Figure 1 at the rear, middle and front of the compartment.

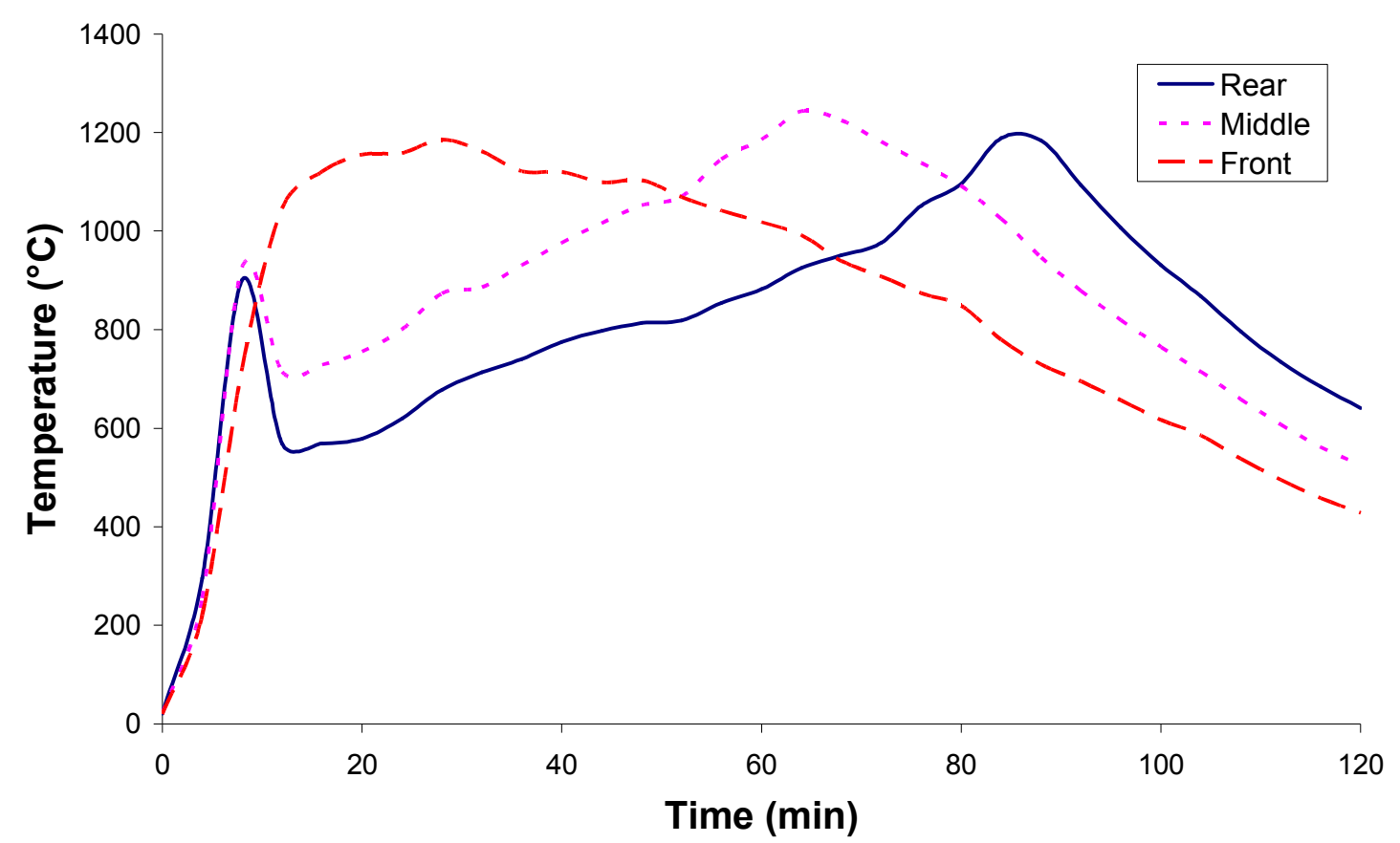

Figure 1: Comparison of temperature-time measurements at three different locations, spaced $8 \mathrm{~m}$ apart, from the rear to the front of the compartment, illustrating nonuniform burning during of wood cribs during the tests of Kirby et al [15].

Thomas and Bennetts [16] conducted a test series of ethanol pool fires in a small rectangular enclosure $(1.5 \mathrm{~m} \times 0.6 \mathrm{~m} \times 0.6 \mathrm{~m})$ to determine the influences of ventilation size and location on the burning rate. They found that there were significant differences in burning rates between having the opening on the short end (long enclosure) or the long side (wide enclosure). They observed temperature differences at different locations up to $500^{\circ} \mathrm{C}$, generally with greater temperatures nearer the vents, as this is where the flames resided more often. This work was continued further [17] with another experimental series of pool fires in a larger, long enclosure ( $8 \mathrm{~m} \times 2 \mathrm{~m}$ x $0.6 \mathrm{~m})$, in which the opening size on the short end was varied. The results obtained were similar to both their earlier work [16] and that of Kirby et al [15]. They conclude that a structural element near the vent would be exposed to more severe conditions than one further inside the compartment. 


\subsection{Travelling Fires}

Since the scale of most enclosures in real buildings is significantly larger than the scale in the few experimental tests available, it is likely that even higher degrees of non-uniformity are to be expected in real fires. Real, large fires that have led to structural failure, such as those in the World Trade Center towers 1, 2 [18] and 7 [19] in New York in September 2001, the Windsor Tower in Madrid, Spain in February 2005 [20] and the Faculty of Architecture at TU Delft in the Netherlands in May 2008 [21] were all observed to travel across floor plates. Due to the travelling nature of the fires, it is likely that temperature distributions during these events were highly non-uniform. While no data exist to validate this, extensive numerical simulations conducted for the World Trade Center investigations by NIST clearly show temperature variations within single compartments of several hundred degrees Celsius $[18,19]$.

\subsection{Fire Tests with High Spatial Resolution}

Traditionally, most fire tests have only limited spatial resolution in temperature measurements. For example, the series of well ventilated fire tests conducted by Steckler et al [22], which are often cited in fire model validation studies, monitored the vertical distribution of gas temperatures at only two locations; at the vent and at one internal corner of the compartment. This low spatial resolution cannot provide the necessary insight into the degree of temperature homogeneity and leaves the uniformity assumption unchallenged.

More recent tests, such as the Dalmarnock Fire Tests [23, 14] in 2006 and the Natural Fire Safety Concept 2 test series at Cardington [24, 13] in 1999, have included a much greater spatial resolution of instrumentation. General overviews of these experimental setups are provided here.

The Dalmarnock Fire Tests, which provide the greatest instrumentation density to date, were conducted in a real high-rise apartment building in Glasgow, UK [23, 14]. The two tests conducted had a realistic fuel load of typical residential/office furnishings. The compartment was $4.75 \mathrm{~m} \times 3.50 \mathrm{~m} \times 2.45 \mathrm{~m}$, containing 20 thermocouple trees, each with 12 thermocouples (placed 0, 0.05, 0.1, 0.2, 0.3, 0.4, 0.6, 0.8, 1.0, 1.3, 1.6 and $2 \mathrm{~m}$ from the ceiling). The Dalmarnock experimental layout is given in Figure 2. Ignition occurred in the waste-paper basket adjacent to the sofa. Two tests were conducted, however only Test One is examined as the fire in the second test was manually suppressed before flashover.

The eight Cardington tests were conducted in a room $12 \mathrm{~m} \mathrm{x} 12 \mathrm{~m} \times 3 \mathrm{~m}$ with uniformly spaced fuel load packages distributed across the floor [24, 13]. Sixteen thermocouple trees containing four thermocouples each were placed on a uniform grid in the compartment to record the gas temperatures, shown in Figure 3. The tests were conducted with various combinations of fuel type, ventilation distribution, and interior lining material. The tests had liquid fuel channels connecting the fuel packages so that ignition and the subsequent burning could be as uniform as possible. 


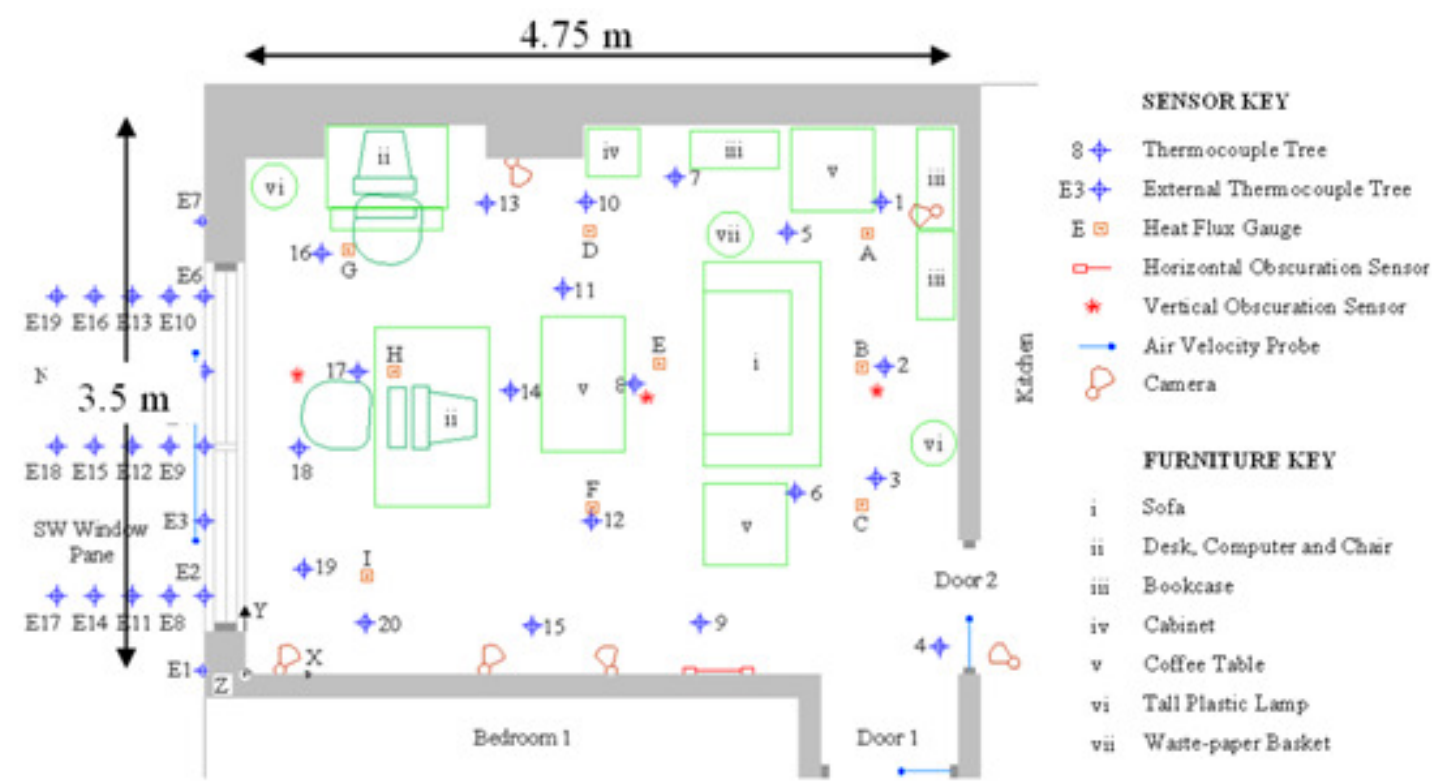

Figure 2: Experimental layout of the Dalmarnock Test One [23, 14]. Locations of the 20 thermocouple trees (each with 12 thermocouples in height) are noted by blue crosses.

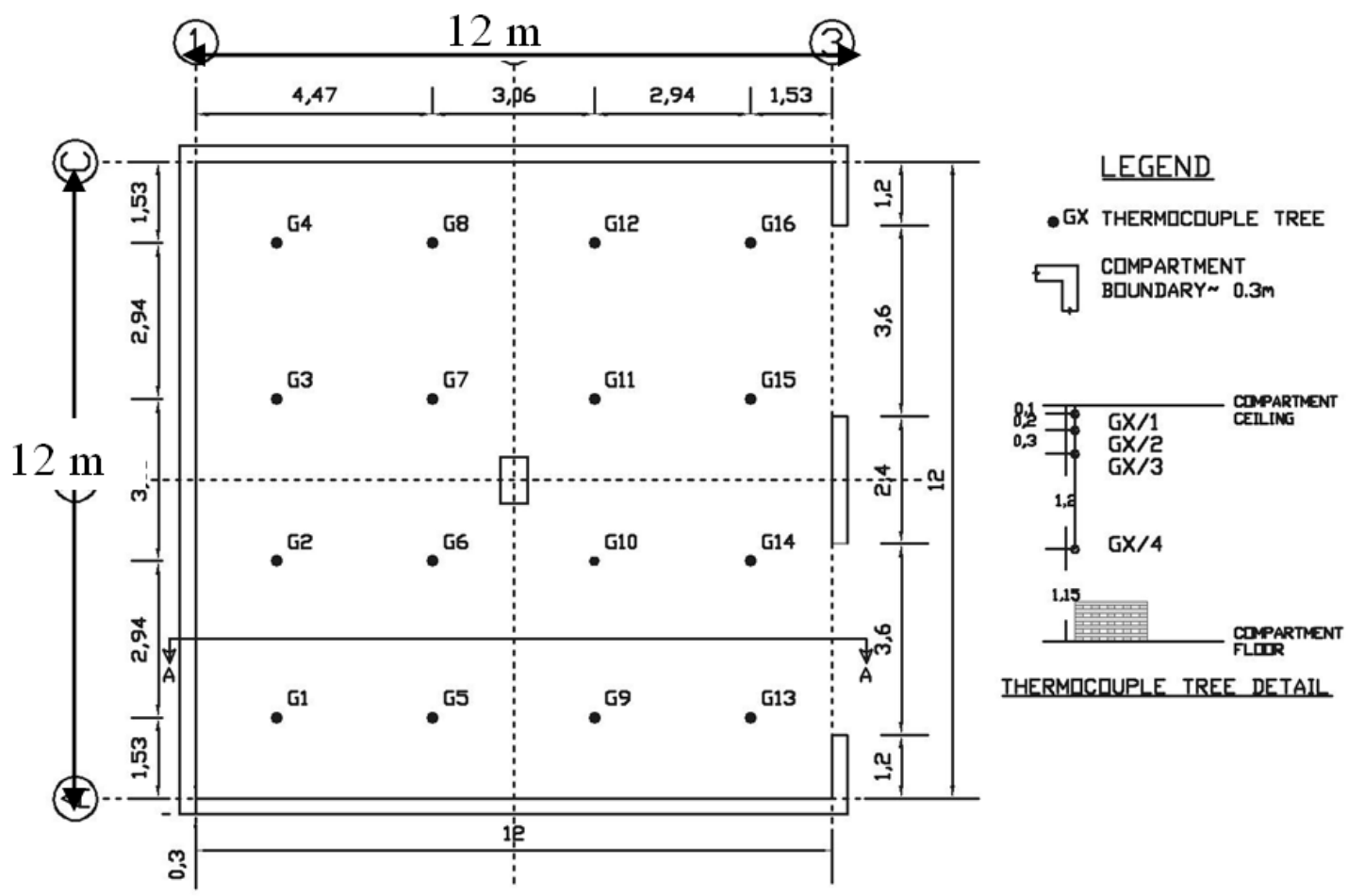

Figure 3: Experimental layout of Cardington Tests [24, 13]. Locations of the 16 thermocouple trees (each with 4 thermocouples in height) are noted by black dots.

The Cardington experiments intended to test two types of compartment insulation; "insulating" (I) and "highly insulating" (HI). However, after Test 1, the "highly insulating" material was placed on the ceiling for all remaining tests, creating an intermediate level of insulation $(\mathrm{I}+)$. The fuel packages were either just wood cribs 
(W) or a combination of wood and plastic cribs $(\mathrm{W}+\mathrm{P})$. The ventilation openings were either fully open on the front $(\mathrm{F})$ of the enclosure or on the front and back $(\mathrm{F}+\mathrm{B})$. A summary of these parameters for all eight tests is given in Table 1.

\begin{tabular}{|l|c|l|l|l|l|l|l|l|}
\hline Test Number & 1 & 2 & 3 & 4 & 5 & 6 & 7 & 8 \\
\hline Fuel Type & W & W & W + P & W & W+P & W & W+P & W + P \\
\hline Insulation Type & I & HI & HI & HI & HI & I & I+ & I+ \\
\hline Opening Location & F & F & F & F+B & F+B & F+B & F+B & F \\
\hline
\end{tabular}

Table 1: Summary of test conditions in Cardington [24, 13].

Both data sets have a sufficient number of data points to allow for a representative statistical analysis. Dalmarnock had 240 points and the Cardington tests each had 64. The Dalmarnock tests have both well distributed measurement points and a high density of instrumentation (5.9 thermocouples $/ \mathrm{m}^{3}$ ). The Cardington tests had well distributed measurement points, but not a high density of instrumentation $(0.15$ thermocouples $/ \mathrm{m}^{3}$ ).

The Dalmarnock test data were corrected for thermocouple radiation errors using the method of Welch et al [13]. The Cardington data have not been corrected. However, Welch et al [13], using Cardington test data, report that typically corrections fall in the range of $10-40^{\circ} \mathrm{C}$, with occasional values as high as $100^{\circ} \mathrm{C}$ for flame temperatures. Additional calculations were performed using the thermocouple corrections for one of the Cardington Tests to confirm that similar results were obtained to those presented in this study.

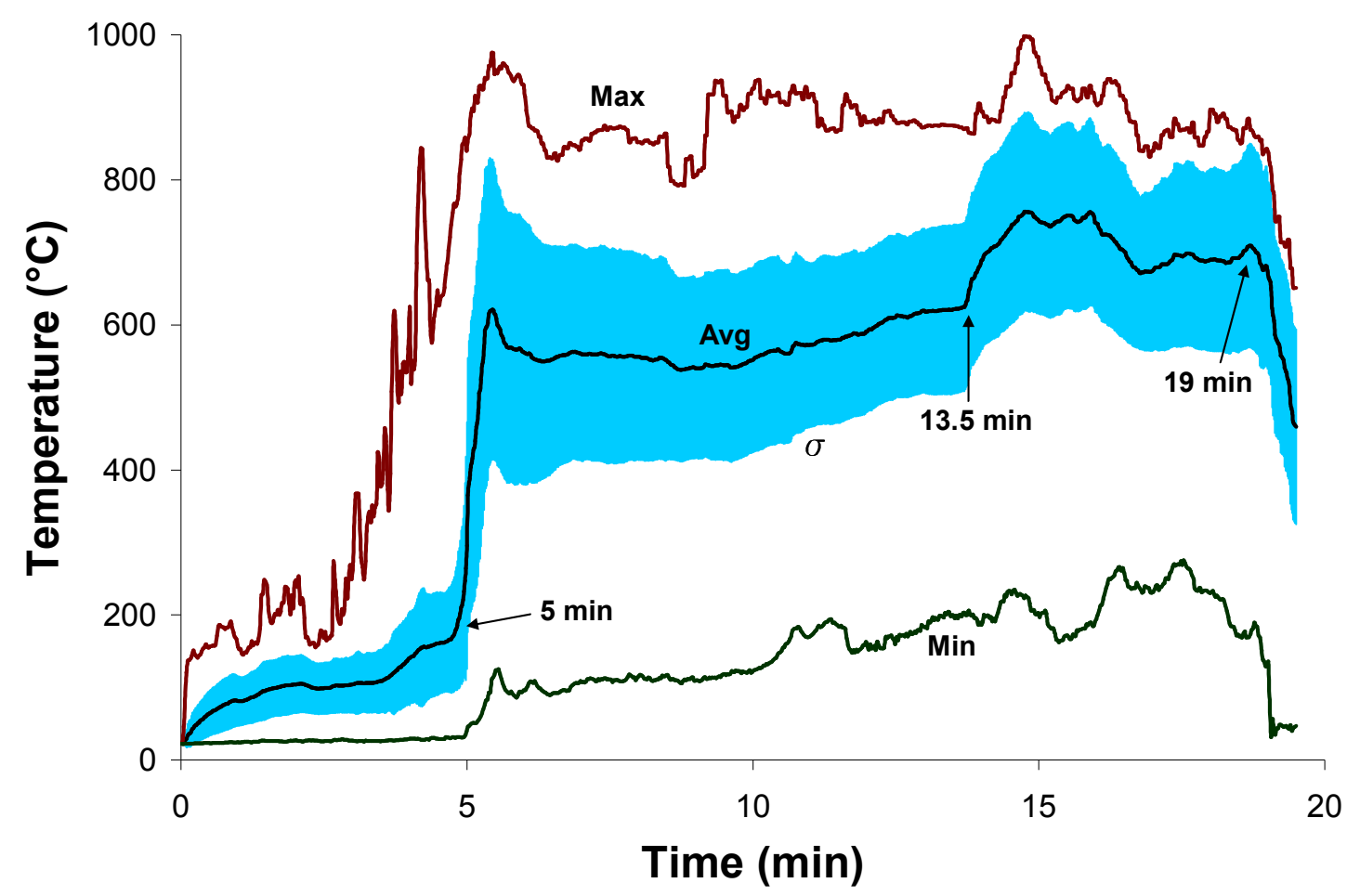

Figure 4: Experimental results of Dalmarnock Test One [23, 14] showing the compartment average, maximum and minimum temperatures, and the standard deviation. Flashover occurred at 5 min, window breakage at $13.5 \mathrm{~min}$, and the fully developed fire lasted until suppression at $19 \mathrm{~min}$. 
The results from Dalmarnock Test One are given in Figure 4. The results are shown with the average compartment temperature and standard deviation in the shaded region, plus the maximum and minimum temperature measurements in the compartment at any given time. Two distinct post-flashover periods can be observed in the Dalmarnock data. The change between the first and second period is caused by window breakage at approximately 13.5 minutes after ignition. The spatial location of the hot and cold spots can be investigated tracking the maximum and minimum temperature curves. Through the test, the maximum temperature was registered at different times in 52 thermocouple locations, distributed over 16 out of the 20 thermocouple trees and all but one of the 12 heights. No particular pattern of where the peak temperatures were located is observed. The minimum temperature was registered at only three different thermocouple locations (thermocouple trees 4, 6, and 18 shown in Figure 2) all at the lowest thermocouple $(0.45 \mathrm{~m}$ above the floor $)$. All three locations are near pathways for make-up air to the fire compartment.

The results for all eight of the Cardington tests are shown in Figure 5. Note that there was a period between 16 and 22 min of Cardington Test 1 where data collection was temporally lost (interpolation is provided).

The general results are summarised in Table 2 which provides the minimum, mean, and maximum standard deviations, as well as the maximum average compartment temperature reached for each test. The standard deviations are only included for portions of the tests where the average compartment temperatures are above $500^{\circ} \mathrm{C}$, as the interest of this examination lay in the post-flashover portion of the experiments. Table 2 also presents averaged values for two different furnace tests conducted on the same wall assembly to the ASTM E119 standard fire in April 2009 [25]. The tests, carried out at a commercial laboratory to provide a rating for a bespoke wall assembly, included nine gas phase thermocouples.

\begin{tabular}{|l|c|c|c|c|}
\hline \multicolumn{1}{|c|}{ Test } & $\begin{array}{c}\text { Min } \sigma \\
\left({ }^{\circ} \mathbf{C}\right)\end{array}$ & $\begin{array}{c}\text { Mean } \sigma \\
\left({ }^{\circ} \mathbf{C}\right)\end{array}$ & $\begin{array}{c}\text { Max } \sigma \\
\left({ }^{\circ} \mathbf{C}\right)\end{array}$ & $\begin{array}{c}\text { Max T } \\
\left({ }^{\circ} \mathbf{C}\right)\end{array}$ \\
\hline Dalmarnock Test One & 105 & 132 & 233 & 733 \\
\hline Cardington 1 & 38 & 84 & 136 & 857 \\
\hline Cardington 2 & 31 & 83 & 153 & 1075 \\
\hline Cardington 3 & 31 & 100 & 208 & 1103 \\
\hline Cardington 4 & 31 & 52 & 93 & 1199 \\
\hline Cardington 5 & 18 & 56 & 135 & 1147 \\
\hline Cardington 6 & 25 & 44 & 129 & 1218 \\
\hline Cardington 7 & 20 & 51 & 159 & 1200 \\
\hline Cardington 8 & 32 & 83 & 213 & 1107 \\
\hline Standard Fire Tests & 8 & 12 & 39 & N/A \\
\hline
\end{tabular}

Table 2: Summary of the temperature measurements of each spatially resolved fire test and the mean values of two standard fire tests to ASTM E119. 

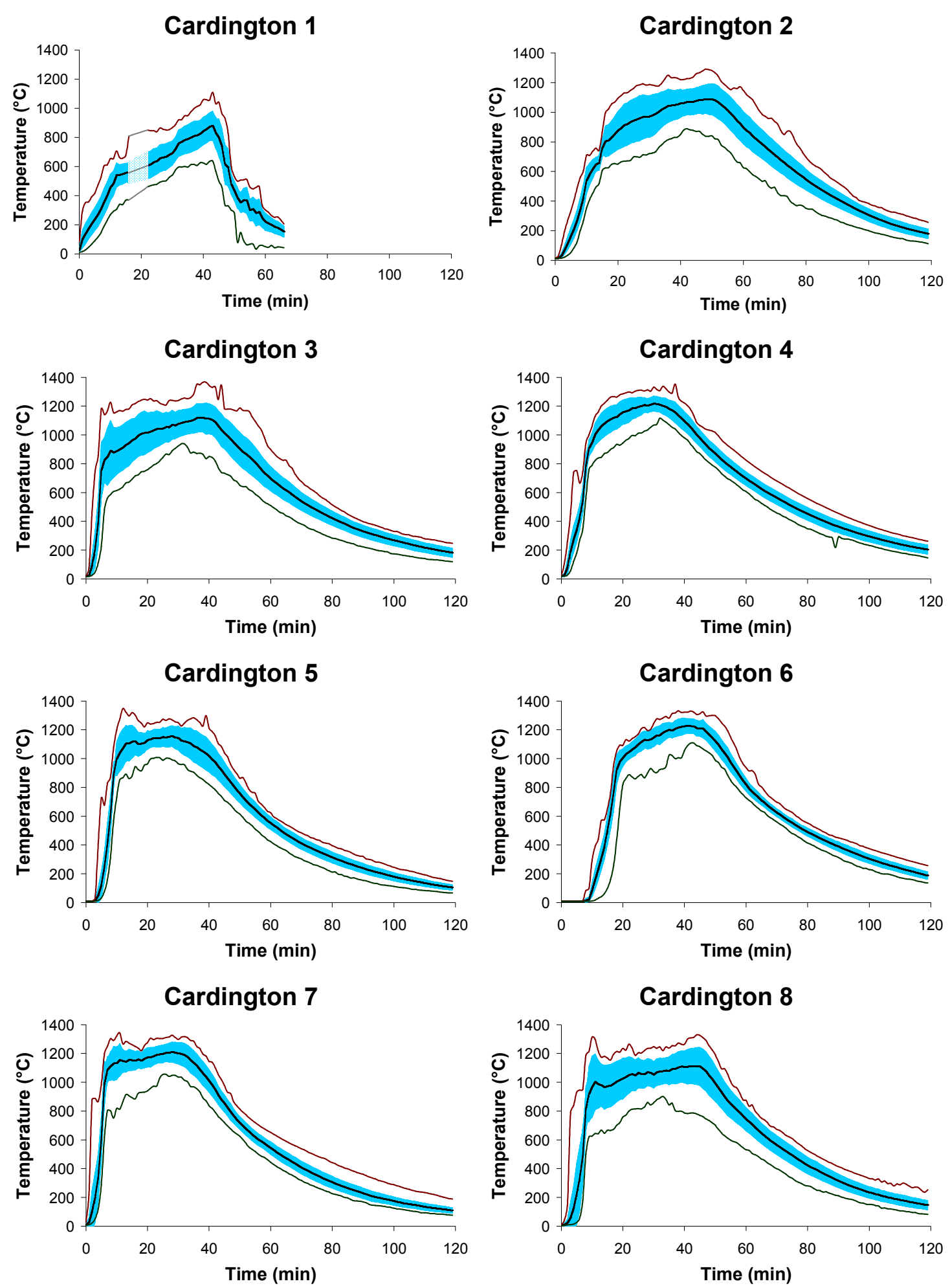

Figure 5: Experimental results of the Cardington Tests [24, 13] showing compartment average, maximum and minimum temperatures, and the standard deviation for each test. See Table 1 for a summary of conditions for each test. 
In addition to the values shown in the Table 2, peak local temperatures range from 23\% (Cardington Test 6) to 75\% (Dalmarnock Test One) higher than the compartment average, with a mean peak increase of $38 \%$ across all tests. Local minimum temperatures range from 29\% (Cardington Test 4) to 99\% (Dalmarnock Test One) below the compartment average, with a mean local minimum temperature of $49 \%$ across all tests.

Higher mean standard deviations are observed in Dalmarnock Test One $\left(132^{\circ} \mathrm{C}\right)$ than all of the Cardington tests (mean of $70^{\circ} \mathrm{C}$ ). This is to be expected for several reasons:

- Dalmarnock Test One had a much higher density of instrumentation than the Cardington tests, making it more likely that the full range of temperature conditions was recorded.

- The thermocouple layout in Dalmarnock Test One covered regions with fuel packages and regions remote from fuel packages. In Cardington, all thermocouples were located above fuel packages and thus the data have a bias towards flame temperatures.

- There were only four different thermocouple heights in the spacing of the Cardington tests, all relatively high, compared to the twelve in Dalmarnock, which were evenly distributed. Thus the Cardington data are biased towards temperatures in the upper portion of the compartment.

- The Dalmarnock Test had a realistic fire scenario where real-world furnishings were arranged in a non-uniform manner and one ignition point was used. In contrast, the Cardington tests had well distributed fuel packages ignited simultaneously.

A clear trend can be seen in the results from Cardington. Tests 4 through 7 all have lower standard deviations (mean of $51^{\circ} \mathrm{C}$ ) than Tests $1,2,3$, and 8 (mean of $88^{\circ} \mathrm{C}$ ). The key difference between the two groups of tests is the ventilation position. Tests 1 , 2,3 , and 8 had ventilation only on one side of the compartment, while Tests 4 through 7 had ventilation at two opposing sides. This fact is in line with the results obtained by the studies previously highlighted with long enclosures $[15,16,17]$. Thus there is heterogeneity in the temperature field due to the depth of the compartment relative to the position of the vents. This effect is less obvious for the tests with ventilation on opposing sides.

These results confirm that there is considerable heterogeneity in the temperature field of post-flashover fires. Real world fires are likely to have a level of dispersion in the temperature field closer to that measured in Dalmarnock Test One than those of the Cardington tests. This is because the high density of instrumentation in Dalmarnock recorded more of the temperature field than those in the Cardington tests, thus a more complete depiction of the variation was established. Furthermore, the fuel types and distributions of real world fires that can cause heterogeneity are more likely to match those of Dalmarnock than the uniformly spaced cribs of Cardington.

It is also worth noting that the tests examined were conducted in compartments of dimensions that are consistent with the homogenous temperature assumption. Thus other compartments with larger or more complex geometries will show broader temperature dispersions. 


\subsection{Data Distributions}

Examination of the statistical distributions of the data from each test provides more insight into the level of uniformity of the temperature field. Figure 6 presents the data distributions for four different times of Dalmarnock Test One with the corresponding normal distribution overlaid. The distributions are shown at four times, evenly spaced between flashover and suppression. The temperature measurements are grouped into $40^{\circ} \mathrm{C}$ bands, as to encompass the experimental uncertainty. If the homogeneous temperature assumption held, there would only be one bar at any given time. Appendix A provides details for the data distributions of the Cardington Tests.

The test data have been presented with standard deviations as a measure of the departure from uniform temperature conditions. For a simplified estimation of the meaning of the standard deviation, it is noted that approximately $65 \%$ of all data fall within the span between one standard deviation on either side of the average and approximately $95 \%$ fall within the same span of two standard deviations.

While the data distributions shown in Figure 6 and Appendix A do not always fit normal distributions, at most times for most tests they are sufficiently close to treat the data as normally distributed for the purposes of this analysis.
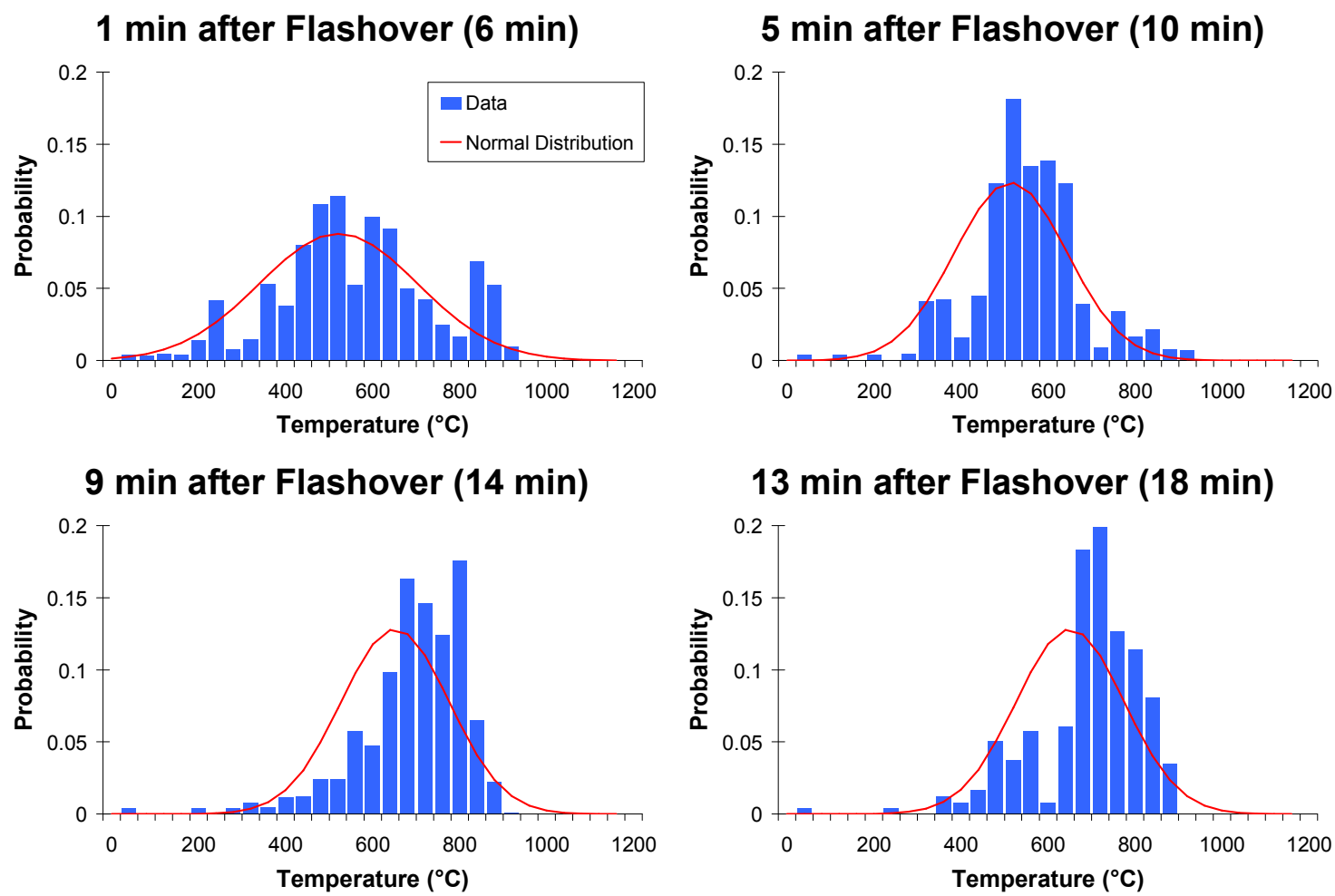

Figure 6: Comparisons of the measured temperature distributions against the associated normal distributions at four minute intervals after flashover for Dalmarnock Test One. 


\subsection{Standard Deviation vs. Temperature Rise}

Figure 7 shows the relationship between the normalised standard deviation, $\sigma^{\prime}$, against the average temperature rise from ambient, $\Delta T_{\text {avg }}$. Each data point represents one instant in time, with one point taken every minute for each test. The normalised standard deviation, $\sigma^{\prime}$, is defined as the standard deviation divided by the average compartment temperature rise above ambient, $\Delta T_{\text {avg }}$. The Cardington tests have been divided into the two ventilation groups previously noted. Cardington $\mathrm{F}$ is the group with ventilation in the front only and Cardington $\mathrm{F}+\mathrm{B}$ is the group with ventilation from both the front and back.

These results indicate that there are significant heterogeneities in the gas field across the whole range of temperatures. Furthermore, the scatter shows a clear trend; the higher the temperature, the lower the normalised standard deviation. The maximum temperature rise, just above $1200^{\circ} \mathrm{C}$, marks the peak flame temperature rise above ambient, which is at the upper end of temperature rises possible in a typical postflashover fire. More intense fires lead to hotter and more uniform conditions in their enclosures, whereas in less intense fires the flame and smoke regions dominate less of the gas field and less uniformity is observed. A clear difference can be seen in the ventilation effect between the two groups from the Cardington tests, with the tests in Cardington $\mathrm{F}$ having less homogeneity than Cardington $\mathrm{F}+\mathrm{B}$. Also the greater degree of heterogeneity from the Dalmarnock test can be seen.

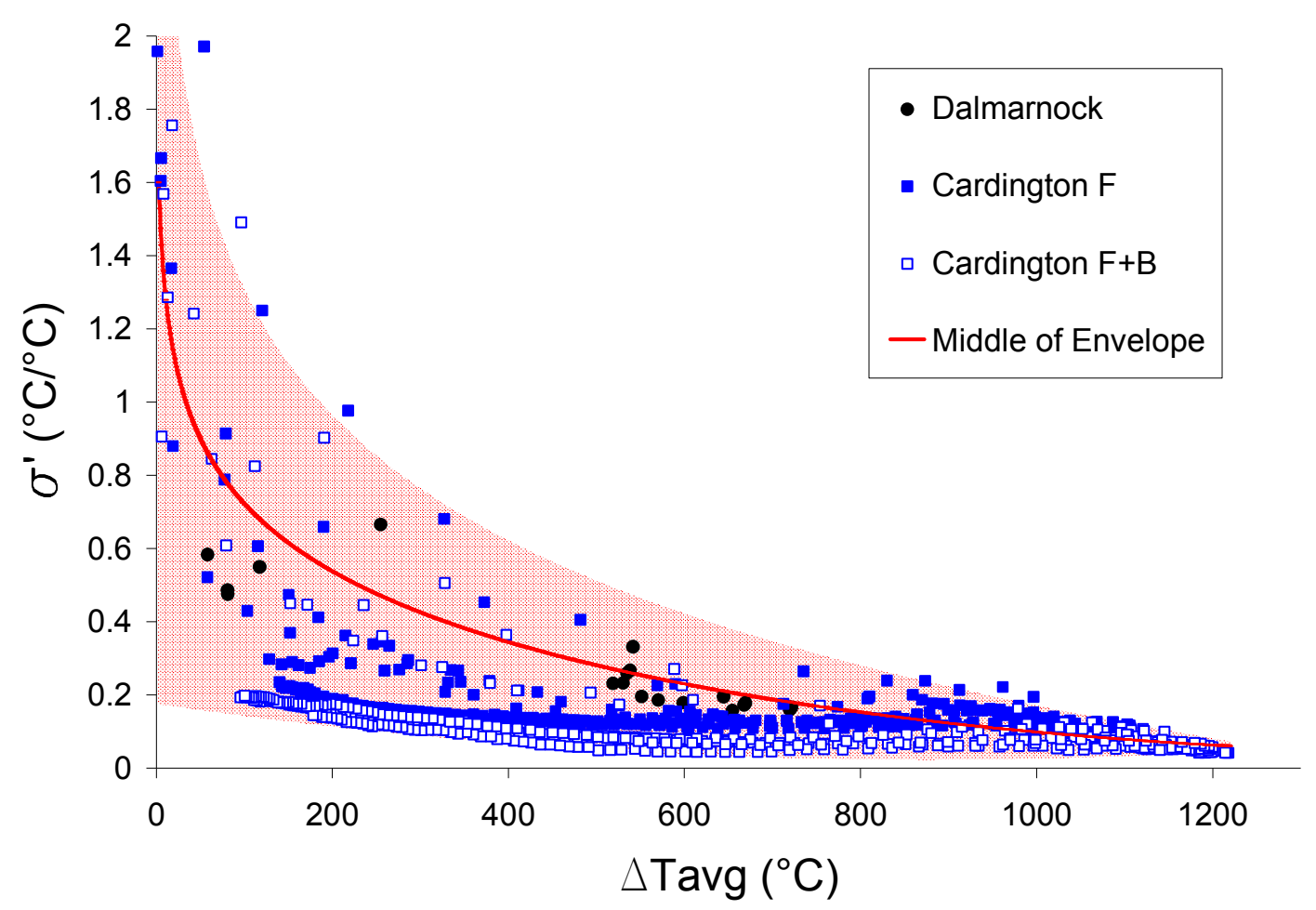

Figure 7: Observed relationship between the normalised standard deviation vs. temperature rise in the spatially resolved fire tests available. 
The shaded region represents an approximate envelope for all of the data points. The best fit equation for the curve that runs through the middle of this envelope is given in Eq. 1.

$$
\sigma^{\prime}=\frac{\sigma}{\Delta T_{\text {avg }}}=1.939-0.266 \ln \left(\Delta T_{\text {avg }}\right)
$$

This curve could be used as a nominal expression of the standard deviation for any temperature-time curve. The shaded envelope could be expected to apply to fires in compartments of similar sizes as those assessed in this paper. For fires in compartments of a much larger size, such as the real ones previously cited $[18,19,20,21]$, the temperature field will likely be much more non-uniform and a travelling fire should be expected. A general discussion of the temperature fields in travelling fires is available in the literature $[26,27]$.

The middle of the envelope has been used in lieu of a regression analysis because the data are biased towards the Cardington tests due to the large number of data points for each test. There were eight Cardington tests and each lasted longer than Dalmarnock Test One. Therefore the shaded envelope was used to eliminate any bias towards the Cardington data. For the reasons already discussed, the Cardington data are deemed inappropriate to express standard deviations for a general, real fire scenario.

\section{EFFECT OF TEMPERATURE HETEROGENEITY ON THE STRUCTURE}

Structural fire resistance calculations are routinely based on averaged temperature values determined on the basis of standard fire tests conducted in test furnaces which are explicitly intended to ensure uniform gas phase temperatures. However, recent studies have shown that the behaviour of certain structural elements are affected by temperature gradients $[28,29]$, thus there is a motivation to revisit the homogeneous temperature assumption. Moreover, the experimental results analysed above are at odds with the traditional assumption of temperature uniformity, thus the effect of this heterogeneity on the heating of structural elements is reviewed here.

A simplistic method for assessing the impact of non-uniform temperature distributions on single structural elements has been adopted. These calculations are intended to provide insight into the performance of simple structures and are not proposed to be a design methodology or calculation guideline. Further research is required to determine true structural response to non-uniform heating as the analysis of the fire test data indicates that the use of a uniform temperature distribution does not capture the true thermal environment of a real fire. Therefore these simplistic calculations have only been adopted for illustrative purposes, to examine trends for structures heated to temperatures above the compartment average.

It is important to clarify that the impact of non-uniform temperature distributions on full structural behaviour is not being assessed here, nor issues associated with details of heat transfer such as soot concentrations or velocities. While these details will have an impact on the heating of structural elements, they are not usually part of standard thermal calculations for the purposes of structural fire analysis. 

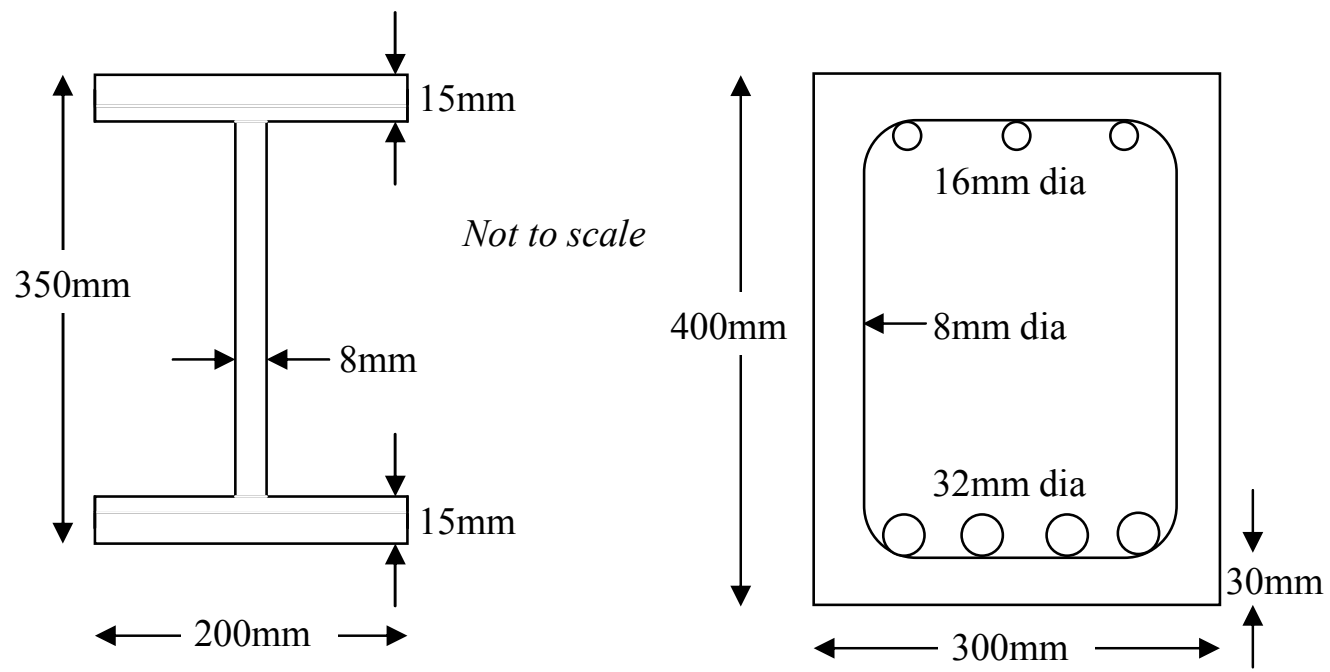

Figure 8: Dimensions of the steel (left) and concrete (right) beams used to determine representative structural responses to the varying temperature distributions.

For illustrative purposes, three simplified examples of structural elements are used: (1) an unprotected steel I-beam, (2) a protected steel I-beam fire rated to $60 \mathrm{~min}$ using a generic insulation, and (3) a concrete beam with a 60 min fire rating. All three beams, with dimensions given in Figure 8, nominally have the same design bending moment capacity under ambient temperature. The beams selected for the analysis are representative of typical beams covering the most common construction types and range of thermal inertias found in real buildings. The unprotected and protected steel beams have the same dimensions, except that an additional layer of fire protection is applied to the protected beam (12 $\mathrm{mm}$ of high density perlite insulation). It is assumed that a concrete floor slab is present above the beams such that the beams are only heated on three sides.

The thermal response of each beam was calculated for a variety of temperaturetime curves above the mean. This information was used in conjunction with thermal definitions of fire resistance based on assumed critical temperatures for each material. Each curve was generated from each experimental data set, starting with the average compartment temperature-time curve, and then adding a fraction of the standard deviation to it, in units of one quarter of the standard deviation. Thus, the first curve analysed for each beam from a given experiment was the average compartment temperature-time curve. The next curve used was the average compartment temperature-time curve plus one quarter of the standard deviation, then the average compartment temperature-time curve plus one half of the standard deviation, and so on until the average compartment temperature-time curve plus two times the standard deviation. Figure 9 illustrates this by showing every second curve used for Cardington 2 . 


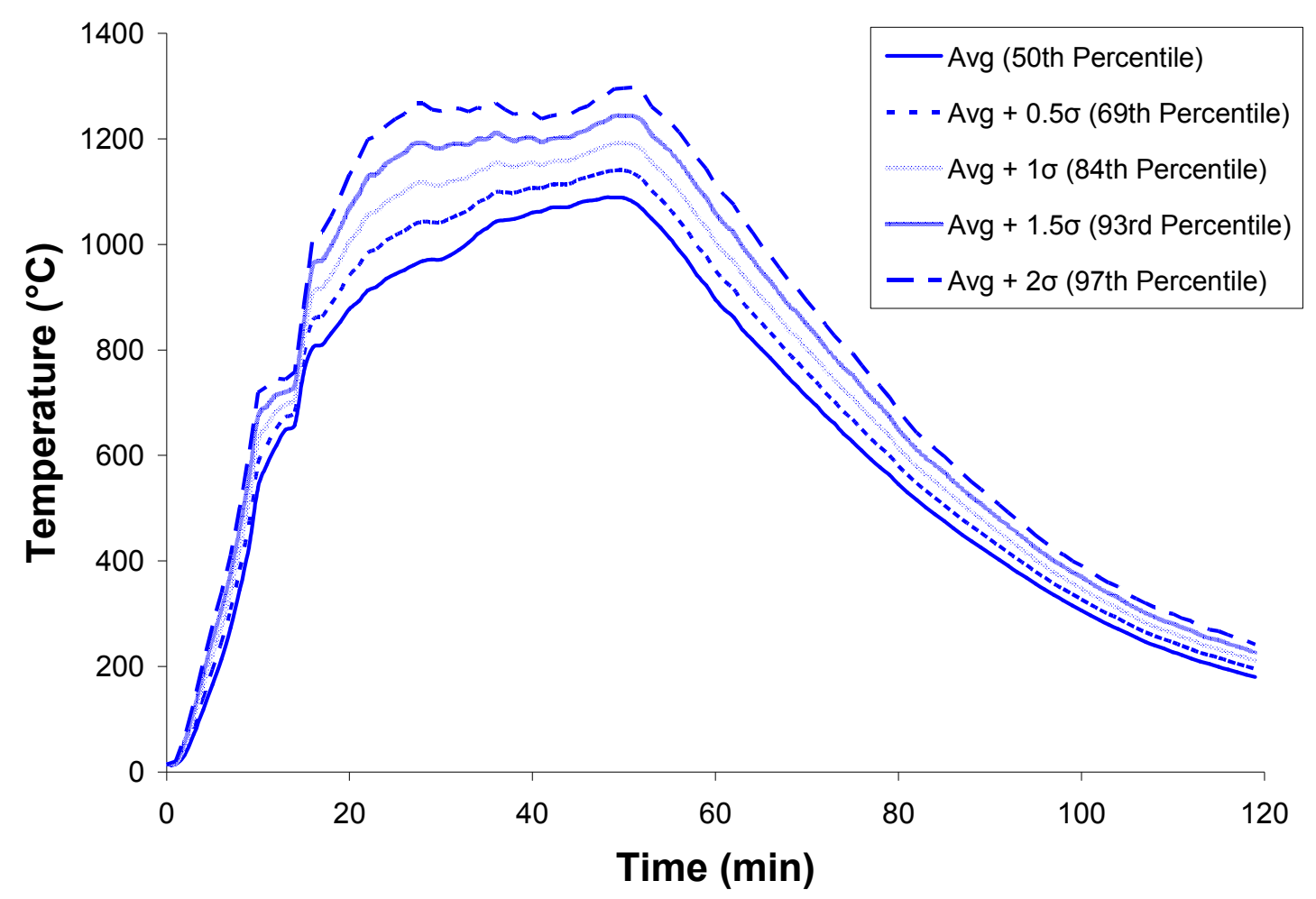

Figure 9: Temperature-time curves for Cardington Test 2, ranging from the average temperature-time curve (representing the $50^{\text {th }}$ percentile) to the average temperaturetime curve plus two standard deviations (representing the $97^{\text {th }}$ percentile). Note that this plot only shows every other curve used for structural assessment.

This approach allows the results to be viewed continuously from the average compartment temperature-time curve through to the average compartment temperaturetime curve plus two standard deviations. This span, if viewed cumulatively, covers the range between the $50^{\text {th }}$ percentile and the $97^{\text {th }}$ percentile.

Only values above the mean have been analysed here. This is to focus on the possibility of current design practices underestimating the effect of fire on structures by use of the average compartment temperature only. The non-uniformity will also result in some elements of structure exposed to less severe conditions than currently assumed using the compartment average. This is not considered here, as a common aim of structural fire engineering is to err on the side of conservatism.

From the percentile temperature-time ranges developed, the peak temperature rise and time to failure, based on an assumed critical temperature, were calculated for each beam and each fire test as a function of the temperature percentile. The unprotected steel beam temperature was calculated by lumped mass heat transfer, as given by Buchanan [30]. The protected steel beam temperatures were also calculated by the lumped mass method given by Buchanan. For the concrete beam, the temperature calculated was that of the internal steel reinforcing bars, assumed to be at the same temperature as the concrete adjacent to it, i.e. the temperature at the extreme underside of the bars. This in-depth temperature of the concrete was calculated with a one-dimensional finite-difference method in explicit form, as given by Incropera et al [31]. 
The time to failure is taken as the time for the steel to heat to $550^{\circ} \mathrm{C}$, as this is normally considered an approximate temperature above which steel loses sufficient strength such that failure of a typical simply-supported beam could occur under the loads assumed to be applied during a fire [5]. Higher temperatures are sometimes used; however $550^{\circ} \mathrm{C}$ is selected here for the purpose of these calculations.

A full description of the calculation methods used is given in Appendix B. It is acknowledged that the calculations and failure criterion are simplistic, and it is important to note that the illustrative approach taken herein does not account for several important issues related to the heating and ultimate response of the structure.

Normalised results for the maximum temperature rise reached against the temperature percentile are shown in Figure 10 for all three beam types. The normalised temperature rise, $\Delta T^{\prime}$, is defined as the steel temperature rise when exposed to the given temperature percentile curve divided by the steel temperature rise when exposed to the average temperature-time curve. In other words, this can be thought to be similar to the steel temperature of an element that is located in a hotter region of the test compartment. This hotter steel temperature would not be calculated if only the average compartment temperature were used. The standard fire is included using the normalised standard deviation in Eq. (1) to generate the full range of temperature-time curves. For guiding purposes, note that if the gas phase were completely homogeneous, a horizontal line at abscissa 1 would be shown.

The results show that the increased temperatures associated with the nonuniformity have a potentially important impact on the structural performance of the beams analysed. Tables 3 through 5 show the results for temperature rise and time to failure for the $80^{\text {th }}$ percentile temperature-time curves (equivalent to the average compartment temperature-time curve plus 0.85 times the standard deviation) for each experiment and the standard fire when compared to the average compartment temperature-time curve. Note that $80^{\text {th }}$ percentile values are often recommended in fire safety engineering for design. For example, in the UK PD7974 recommends fire loads for structural fire analysis to be the $80^{\text {th }}$ percentile values [32].

Compared to the calculations using the average compartment temperature measurements, the results at the $80^{\text {th }}$ percentile show that a higher temperature region in a compartment could result in a steel temperature rise up to $25 \%$ higher $(15 \%$ for the unprotected steel beam, $18 \%$ for the protected steel beam, and $25 \%$ for a concrete beam) or reach the time to failure, i.e. the fire resistance time, up to $31 \%$ faster (31\% for the unprotected steel beam, $15 \%$ for the protected steel beam, and $22 \%$ for the concrete beam). For the $95^{\text {th }}$ percentile, temperature rises can be up to $60 \%$ higher and fire resistance times $55 \%$ shorter. 


\section{Unprotected Steel}

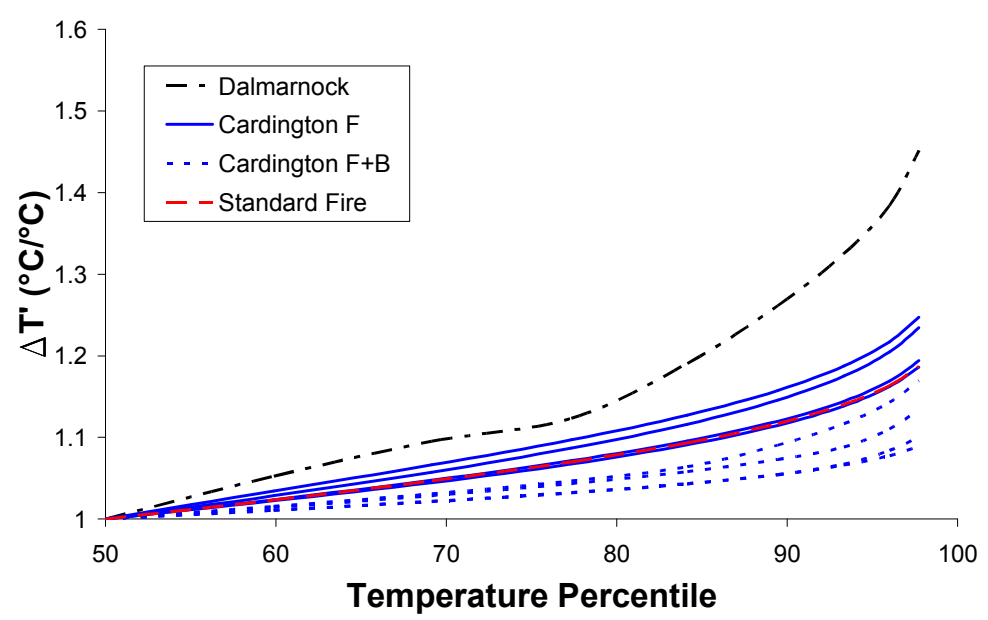

Protected Steel

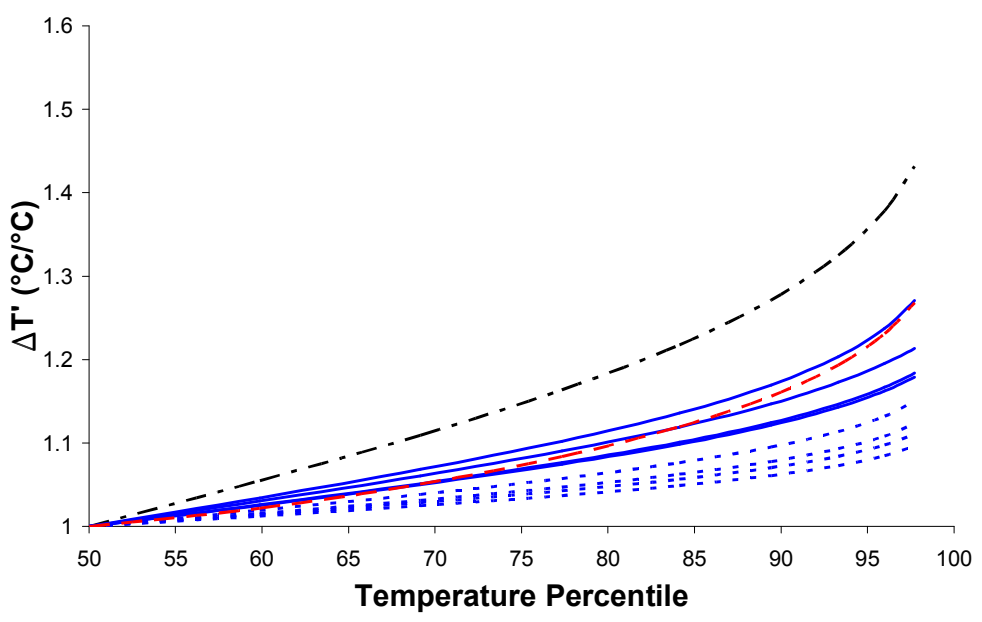

\section{Concrete}

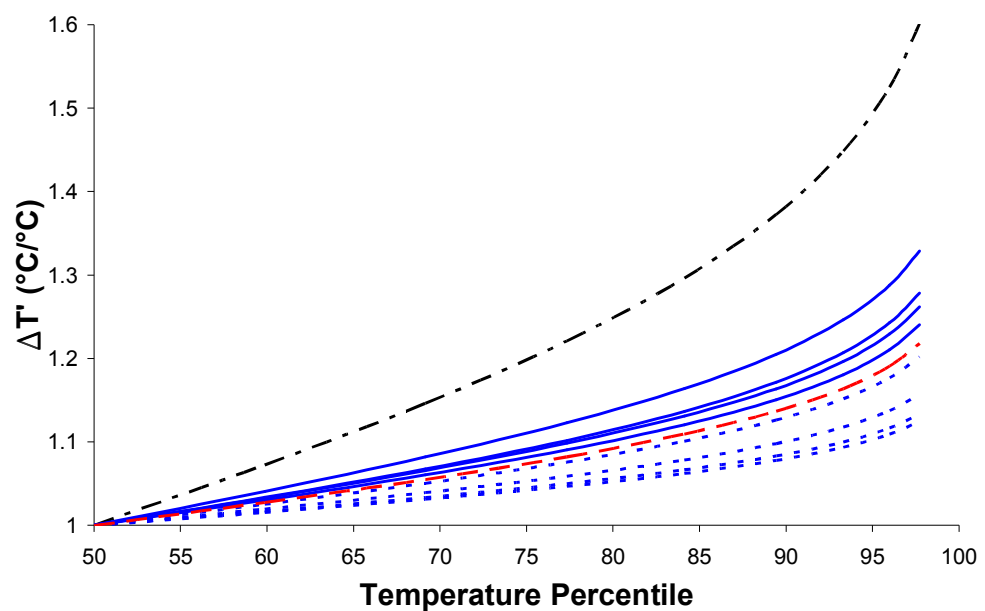

Figure 10: Results of the normalised temperature rise for each type of beam analysed. Note that a horizontal line at abscissa 1 would represent a homogeneous temperature field. 


\begin{tabular}{|l|c|c|c|c|}
\cline { 2 - 5 } \multicolumn{1}{c|}{} & \multicolumn{2}{l|}{ Temperature Rise } & \multicolumn{2}{l|}{ Time to Failure } \\
\hline Test & Difference & $\%$ Increase & Difference & \% Decrease \\
\hline Dalmarnock Test One & $96^{\circ} \mathrm{C}$ & $15 \%$ & $3.8 \mathrm{~min}$ & $26 \%$ \\
\hline Cardington 1 & $91^{\circ} \mathrm{C}$ & $11 \%$ & $4.5 \mathrm{~min}$ & $21 \%$ \\
\hline Cardington 2 & $87^{\circ} \mathrm{C}$ & $8 \%$ & $1.0 \mathrm{~min}$ & $6 \%$ \\
\hline Cardington 3 & $84^{\circ} \mathrm{C}$ & $8 \%$ & $1.1 \mathrm{~min}$ & $15 \%$ \\
\hline Cardington 4 & $44^{\circ} \mathrm{C}$ & $4 \%$ & $0.5 \mathrm{~min}$ & $5 \%$ \\
\hline Cardington 5 & $61^{\circ} \mathrm{C}$ & $5 \%$ & $0.5 \mathrm{~min}$ & $5 \%$ \\
\hline Cardington 6 & $44^{\circ} \mathrm{C}$ & $4 \%$ & $0.7 \mathrm{~min}$ & $4 \%$ \\
\hline Cardington 7 & $59^{\circ} \mathrm{C}$ & $5 \%$ & $0.5 \mathrm{~min}$ & $8 \%$ \\
\hline Cardington 8 & $109^{\circ} \mathrm{C}$ & $10 \%$ & $0.9 \mathrm{~min}$ & $9 \%$ \\
\hline Standard Fire & $81^{\circ} \mathrm{C}$ & $8 \%$ & $3.1 \mathrm{~min}$ & $31 \%$ \\
\hline
\end{tabular}

Table 3: Summary of the unprotected steel beam results for temperature rise and time to failure for the $80^{\text {th }}$ percentile temperature-time curve.

\begin{tabular}{|l|c|c|c|c|}
\cline { 2 - 5 } \multicolumn{1}{c|}{} & \multicolumn{2}{l|}{ Temperature Rise } & \multicolumn{2}{l|}{ Time to Failure } \\
\hline Test & Difference & $\%$ Increase & Difference & \% Decrease \\
\hline Dalmarnock Test One & $30^{\circ} \mathrm{C}$ & $18 \%$ & Did not fail & Did not fail \\
\hline Cardington 1 & $43^{\circ} \mathrm{C}$ & $12 \%$ & Did not fail & Did not fail \\
\hline Cardington 2 & $51^{\circ} \mathrm{C}$ & $8 \%$ & $5.2 \mathrm{~min}$ & $10 \%$ \\
\hline Cardington 3 & $59^{\circ} \mathrm{C}$ & $10 \%$ & $5.6 \mathrm{~min}$ & $12 \%$ \\
\hline Cardington 4 & $29^{\circ} \mathrm{C}$ & $5 \%$ & $3.1 \mathrm{~min}$ & $7 \%$ \\
\hline Cardington 5 & $36^{\circ} \mathrm{C}$ & $6 \%$ & $6.4 \mathrm{~min}$ & $13 \%$ \\
\hline Cardington 6 & $25^{\circ} \mathrm{C}$ & $4 \%$ & $2.6 \mathrm{~min}$ & $5 \%$ \\
\hline Cardington 7 & $31^{\circ} \mathrm{C}$ & $5 \%$ & $3.7 \mathrm{~min}$ & $9 \%$ \\
\hline Cardington 8 & $52^{\circ} \mathrm{C}$ & $9 \%$ & $5.3 \mathrm{~min}$ & $11 \%$ \\
\hline Standard Fire & $71^{\circ} \mathrm{C}$ & $10 \%$ & $8.9 \mathrm{~min}$ & $15 \%$ \\
\hline
\end{tabular}

Table 4: Summary of the protected steel beam results for temperature rise and time to failure for the $80^{\text {th }}$ percentile temperature-time curve.

\begin{tabular}{|l|c|c|c|c|}
\cline { 2 - 5 } \multicolumn{1}{c|}{} & \multicolumn{2}{l|}{ Temperature Rise } & \multicolumn{2}{l|}{ Time to Failure } \\
\hline Test & Difference & \% Increase & Difference & \% Decrease \\
\hline Dalmarnock Test One & $47^{\circ} \mathrm{C}$ & $25 \%$ & Did not fail & Did not fail \\
\hline Cardington 1 & $53^{\circ} \mathrm{C}$ & $14 \%$ & Did not fail & Did not fail \\
\hline Cardington 2 & $60^{\circ} \mathrm{C}$ & $10 \%$ & $7.0 \mathrm{~min}$ & $13 \%$ \\
\hline Cardington 3 & $67^{\circ} \mathrm{C}$ & $12 \%$ & $6.5 \mathrm{~min}$ & $15 \%$ \\
\hline Cardington 4 & $34^{\circ} \mathrm{C}$ & $6 \%$ & $2.8 \mathrm{~min}$ & $8 \%$ \\
\hline Cardington 5 & $48^{\circ} \mathrm{C}$ & $9 \%$ & $5.6 \mathrm{~min}$ & $14 \%$ \\
\hline Cardington 6 & $33^{\circ} \mathrm{C}$ & $5 \%$ & $2.5 \mathrm{~min}$ & $6 \%$ \\
\hline Cardington 7 & $40^{\circ} \mathrm{C}$ & $7 \%$ & $3.0 \mathrm{~min}$ & $9 \%$ \\
\hline Cardington 8 & $66^{\circ} \mathrm{C}$ & $11 \%$ & $6.7 \mathrm{~min}$ & $15 \%$ \\
\hline Standard Fire & $63^{\circ} \mathrm{C}$ & $9 \%$ & $15.3 \mathrm{~min}$ & $22 \%$ \\
\hline
\end{tabular}

Table 5: Summary of the concrete beam results for temperature rise and time to failure for the $80^{\text {th }}$ percentile temperature-time curve. 
With respect to the heat transfer analysis, the methods used are analogous to those employed for uniform temperature fields, but because they are applied to a range of temperature-time curves above the compartment average, the cumulative results provide insight into the possible heating from heterogeneous temperature fields. It is noted that fully spatially resolved heat transfer analyses, as described by Jowsey [28], were not conducted. That type of analysis could be applied to calculate the non-uniform heating from a heterogeneous temperature field, but requires spatially resolved optical properties and velocities of the combustions gases, which were not available for all of the tests reviewed in this paper.

In terms of the structural behaviour, only a single element has been considered with a fixed temperature representing the failure criterion, thus the method ignores a range of possible structural behaviours including axial restraint, membrane actions, and flexural continuity over multiple spans in a real building. Many more detailed methods and criteria exist to determine the impact of fire on structures for defining their fire resistance [30]. However, given that generic structural elements are being assessed for illustrative purposes only, the current analysis provides useful insights.

Although not assessed here, the location of the thermal non-homogeneities along a structural member is potentially important, since localised heating in regions of lower applied stresses may be less critical for structural performance than in regions of high applied stress. A more detailed structural analysis accounting for thermal nonhomogeneities would be required to investigate the potential impacts of non-uniform heating on full-structure response to fire.

\section{CONCLUSIONS}

The statistical analysis of the fire tests examined shows that there is considerable non-uniformity in the temperature field of real post-flashover fires. Peak local temperatures range from $23 \%$ to $75 \%$ higher than the compartment average, with a mean peak increase of $38 \%$. Local minimum temperatures range from $29 \%$ to $99 \%$ below the spatial average, with a mean local minimum temperature of $49 \%$ below the compartment average. This is in contrast to the common assumption of a homogenous temperature field often used in quantification and modelling of post-flashover compartment fires.

The contradictions between the assumption of homogeneity and measured heterogeneity means that fire tests with limited spatial instrumentation, which are often only reported as average temperature measurements, may lead to erroneous conclusions. If fire tests are not well instrumented, it may be difficult to determine which portion of the temperature distribution has been measured and which parts were not recorded. It has been shown here with the data from the most densely instrumented experiments to date, that this range is on the order of hundreds of degrees Celsius.

This heterogeneity can have a potentially non-negligible impact on the structural fire resistance of steel or concrete beams. This is noticeable in increased structural temperatures (up to $25 \%$ higher) and shorter times to failure (up to $31 \%$ faster) at the $80^{\text {th }}$ percentile values compared to those that would be calculated assuming the average compartment temperature. These results along with the recent studies showing some 
structural elements are adversely affected by temperature gradients gives motivation to revisit the homogeneous temperature assumption and further explore its ramifications.

While the full implications of the temperature heterogeneity of post-flashover fires are not explored here, it is apparent that post-flashover fires do not reach uniform conditions. The presented results highlight the need to increase the spatial resolution of measurements in fire experiments to capture the full variation within the compartment. Spatially resolved data can lead to a rational statistical approach to fire behaviour when applied to fire safety and structural engineering applications.

\section{ACKNOWLEDGEMENTS}

The authors would like to thank Susan Deeny and Angus Law of the University of Edinburgh and Linus Lim of Arup Fire for discussions, ideas, and resources as well as Wolfram Jahn of the University of Edinburgh and Allan Jowsey of Arup Fire for their revisions of the manuscript. Further thanks go to Barbara Lane and Arup Fire for supporting this work and making it possible.

\section{REFERENCES}

[1] B. Karlsson and J. G. Quintiere, Enclosure Fire Dynamics. CRC Press, 1999.

[2] P. H. Thomas, "Modelling of compartment fires," Fire Safety Journal, vol. 5, no. 3-4, pp. $181-190,1983$.

[3] S.-E. Magnusson and S. Thelandersson, "Temperature-time curves for the complete process of fire development - a theoretical study of wood fuels in enclosed spaces," Acta Polytechnica Scandinavica, Stockholm, vol. Ci 65, 1970.

[4] V. Babrauskas and R. B. Williamson, "Post-flashover compartment fires: Basis of a theoretical model," Fire and Materials, vol. 2, no. 2, pp. 39-53, 1978.

[5] D. Drysdale, An Introduction to Fire Dynamics. John Wiley \& Sons, 2nd ed., 1998.

[6] J.-M. Franssen, "Improvement of the parametric fire of eurocode 1 based on experimental test results," Proceedings of the 6th IAFSS Symposium, pp. 927938, 1999. doi:10.3801/IAFSS.FSS.6-927.

[7] ISO 834-1: Fire-resistance tests - Elements of building construction, Part 1: General Requirements. ISO, 1999.

[8] BS 476: Part 20 Fire tests on building materials and structures. BSI, 1987.

[9] ASTM E119 - 08a, Standard Test Methods for Fire Tests of Building Construction and Materials. ASTM, 1987.

[10] N. R. Keltner, J. V. Beck, and J. T. Nakos, "Using directional flame thermometers for measuring thermal exposure," ASTM E5 - Advances in the State of the Art of Fire Testing, Miami, Florida, 2008.

[11] T. Z. Harmathy, "Postflashover fires - an overview of the research at the national research council of canada (nrcc), 1970-1985," Fire Technology, vol. 22, pp. 210-233, Aug. 1986.

[12] B. Bøhm and S. Hadvig, "Nonconventional fully developed polyethylene and wood compartment fires," Combustion and Flame, vol. 44, no. 1-3, pp. 201 $221,1982$. 
[13] S. Welch, A. Jowsey, S. Deeny, R. Morgan, and J. Torero, "Bre large compartment fire tests-characterising post-flashover fires for model validation," Fire Safety Journal, vol. 42, no. 8, pp. 548 - 567, 2007.

[14] C. Abecassis-Empis, P. Reszka, T. Steinhaus, A. Cowlard, H. Biteau, S. Welch, G. Rein, and J. Torero, "Characterisation of dalmarnock fire test one," Experimental Thermal and Fluid Science, vol. 32, no. 7, pp. 1334 - 1343, 2008.

[15] B. R. Kirby, D. E. Wainman, L. N. Tomlinson, T. R. Kay, and B. N. Peacock, Natural Fires in Large Scale Compartments - A British Steel Technical, Fire Research Station Collaborative Project. BSC, 1994.

[16] I. Thomas and I. Bennetts, "Fires in enclosures with single ventilation openings comparison of long and wide enclosures," Proceedings of the 6th IAFSS Symposium, pp. 941-952, 1999. doi:10.3801/IAFSS.FSS.6-941.

[17] I. Thomas, K. Moinuddin, and I. Bennetts, "Fires development in a deep enclosure," Proceedings of the 8th IAFSS Symposium, pp. 1277-1288, 2005. doi:10.3801/IAFSS.FSS.8-1277.

[18] R. G. Gann, A. Hamins, K. B. McGratten, G. W. Mulholland, H. E. Nelson, T. J. Ohlemiller, W. M. Pitts, and K. R. Prasad, Reconstruction of the Fires in the World Trade Center Towers. NIST NCSTAR 1-5, 2005.

[19] T. P. McAllister, R. G. Gann, J. D. Averill, J. L. Gross, W. L. Grosshandler, J. R. Lawson, K. B. McGratten, W. M. Pitts, K. R. Prasad, and F. H. Sadek, Fire Response and Probable Collapse Sequence of the World Trade Center Building 7. NIST NCSTAR 1-9, 2008.

[20] I. Fletcher, S. Welch, J. Capote, D. Alvear, and M. Lázaro, "Model-based analysis of a concrete building subjected to fire," Advanced Research Workshop on Fire Computer Modelling, Santander, Spain, 2007, http://www.era.lib.ed.ac.uk/handle/1842/1988.

[21] M. Zannoni, G. Bos, K. Engel, and U. Rosenthal, Brand bij Bouwkunde. COT Instituut voor Veilingheids - en Crisismanagement, 2008.

[22] K. D. Steckler, J. G. Quintiere, and W. J. Rinkinen, Flow Induced by Fire in a Compartment. NBSIR 82-2520, 1982.

[23] G. Rein, C. Abecassis-Empis, and R. Carvel, eds., The Dalmarnock Fire Tests: Experiments and Modelling. School of Engineering and Electronics, University of Edinburgh, 2007.

[24] T. Lennon and D. Moore, "The natural fire safety concept - full-scale tests at cardington," Fire Safety Journal, vol. 38, no. 7, pp. 623 - 643, 2003.

[25] Internal Report, Arup Fire, San Francisco. 2009.

[26] G. Rein, X. Zhang, P. Williams, B. Hume, A. Heise, A. Jowsey, B. Lane, and J. L. Torero, "Multi-story fire analysis for high-rise buildings," Proceedings of the 11th International Interflam Conference, London, 2007, http://www.era.lib.ed.ac.uk/handle/1842/1980.

[27] J. Stern-Gottfried, G. Rein, B. Lane, and J. L. Torrero, "An innovative approach to design fires for structural analysis of non-conventional buildings: A case study," Application of Structural Fire Engineering, Prague, Czech Republic, 2009, http://eurofiredesign.fsv.cvut.cz/Proceedings/1st_session.pdf.

[28] A. Jowsey, Fire Imposed Heat Fluxes for Structural Analysis. PhD thesis, The University of Edinburgh, 2006, http://www.era.lib.ed.ac.uk/handle/1842/1480.

[29] M. Gillie, C. Röben, A. Ervine, and S. Kirkpatrick, "The effects of non-uniform fires on structural behaviour," Proceedings of the Fith International Conference on Structures in Fire, Singapore, 2008.

[30] A. Buchanan, Structural Design for Fire Safety. John Wiley \& Sons, 2002. 
J. Stern-Gottfried, G. Rein, L. A. Bisby, J. L. Torero. Experimental review of the homogeneous temperature assumption in post-flashover compartment fires, Fire Safety Journal 2010; 45:249. doi: $10.1016 / j$.firesaf.2010.03.007. Open access version at http://www.era.lib.ed.ac.uk/handle/1842/1152

[31] F. Incropera, D. DeWitt, T. Bergman, and A. Lavine, Fundamentals of Heat and Mass Transfer. John Wiley \& Sons, 2007.

[32] PD7974-0:2002 Application of fire safety engineering principles to the design of buildings - Part 0: Guide to design framework and fire safety engineering procedures. BSI, 2002. 


\section{APPENDIX A: CARDINGTON DATA DISTRIBUTIONS}

The nine fire experiments reviewed were analysed in terms of their data distributions. Figure 6 presents the data for Dalmarnock, while the equivalent data for all the Cardington tests are given here in Figures A1 and A2. As with the Dalmarnock data, the Cardington data are broken into $40^{\circ} \mathrm{C}$ segments for the distributions. The distributions are given at three times: 10 minutes, 30 minutes, and 50 minutes. These times were selected to encompass the main periods of post-flashover burning across all tests.

Figure A1 presents the data distributions for the four Cardington tests with ventilation at one side only $(\mathrm{F})$, while Figure A2 presents the data distributions with ventilation on opposing sides $(\mathrm{F}+\mathrm{B})$. The $\mathrm{F}$ data show a greater span in the distributions than the $\mathrm{F}+\mathrm{B}$ data. 

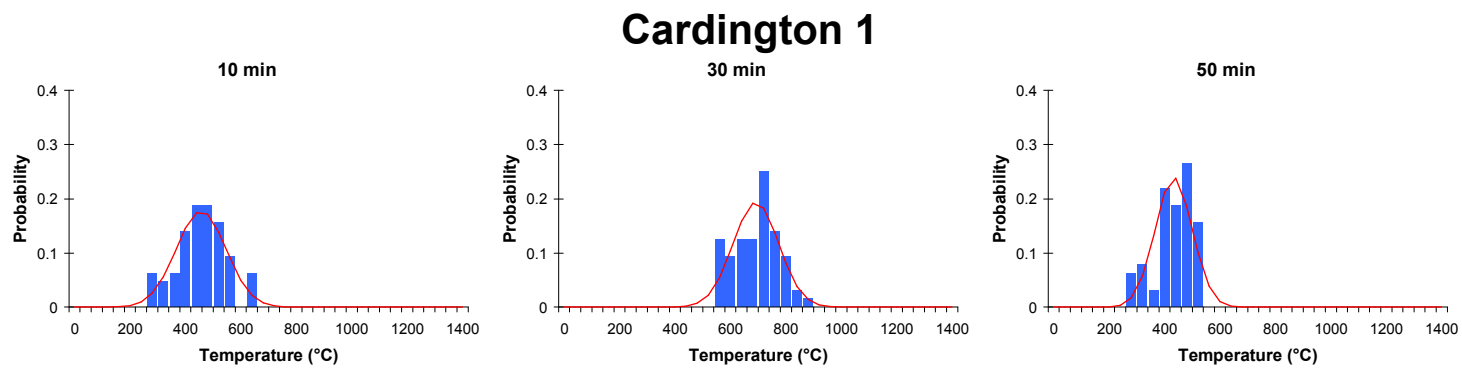

\section{Cardington 2}
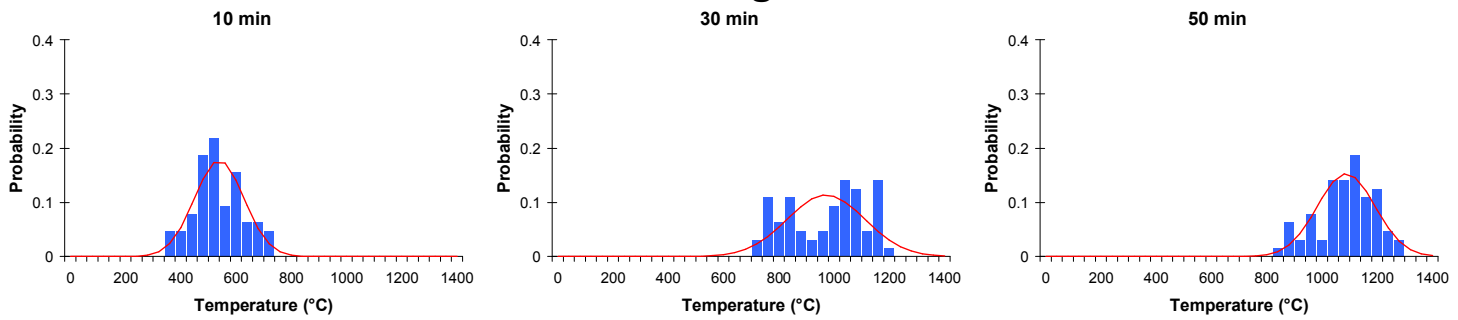

\section{Cardington 3}
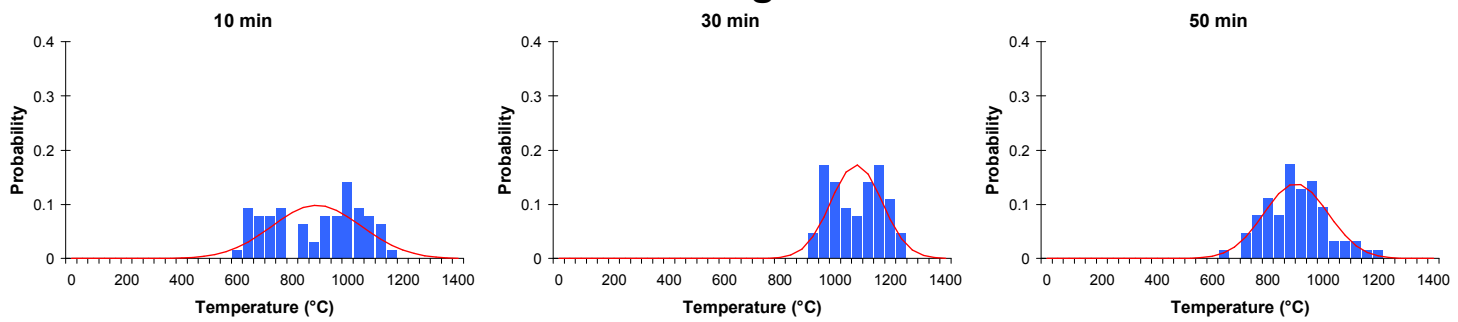

\section{Cardington 8}
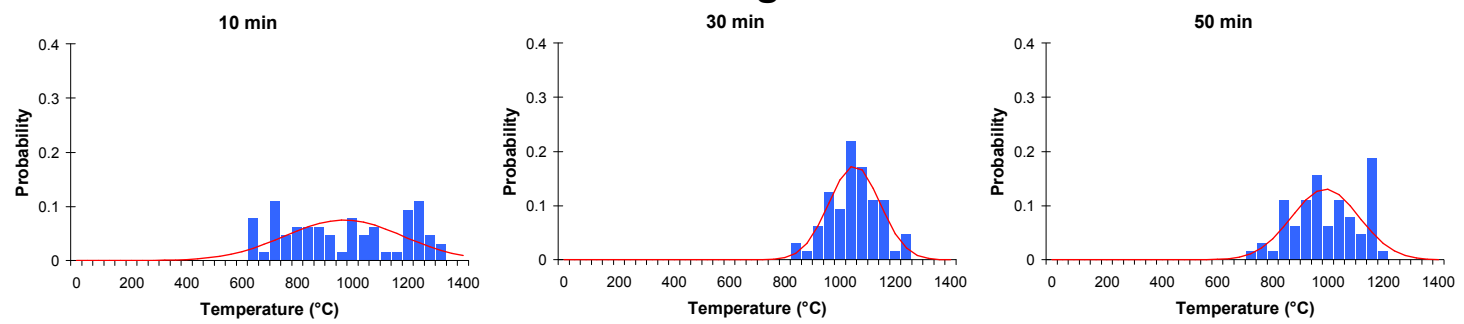

Figure A1: Data distributions with equivalent normal distributions for Cardington Tests with ventilation on one side only (Tests 1, 2, 3 and 8). 

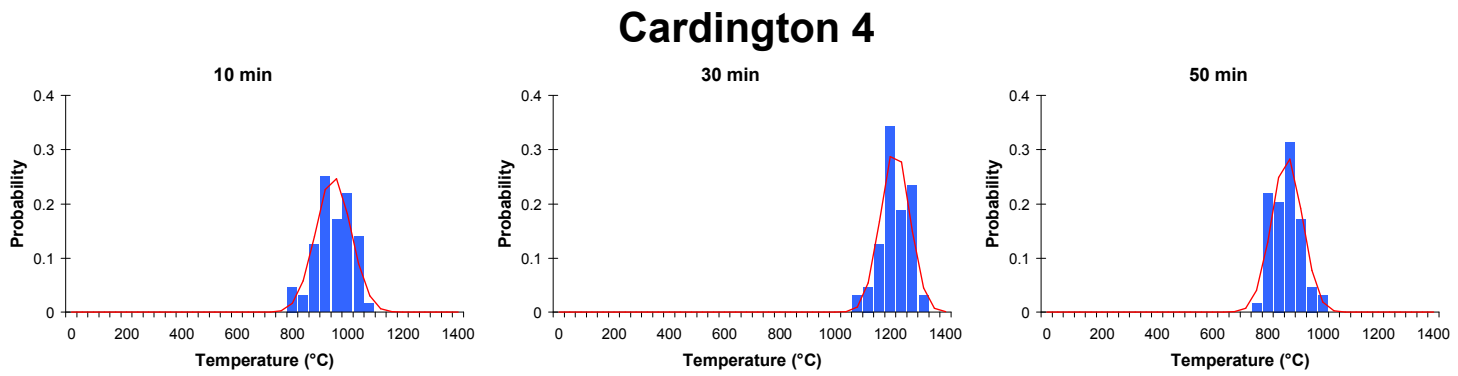

\section{Cardington 5}
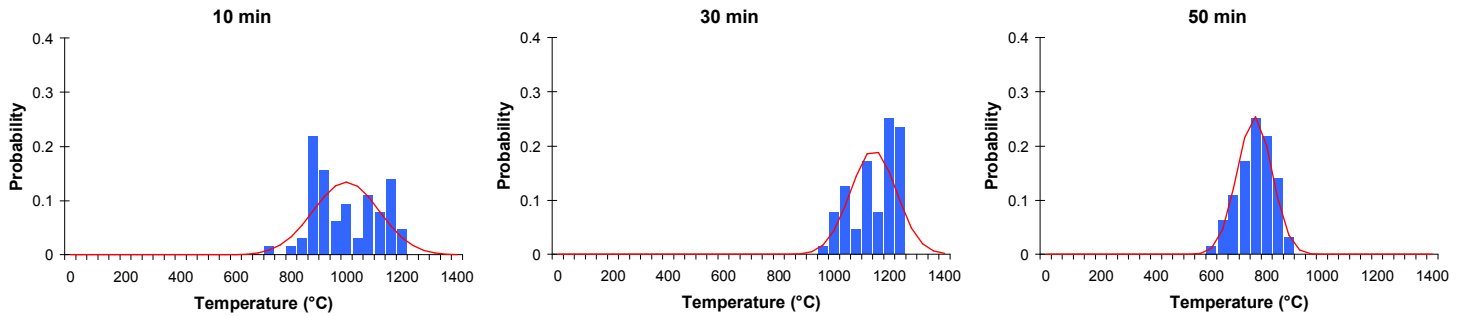

\section{Cardington 6}
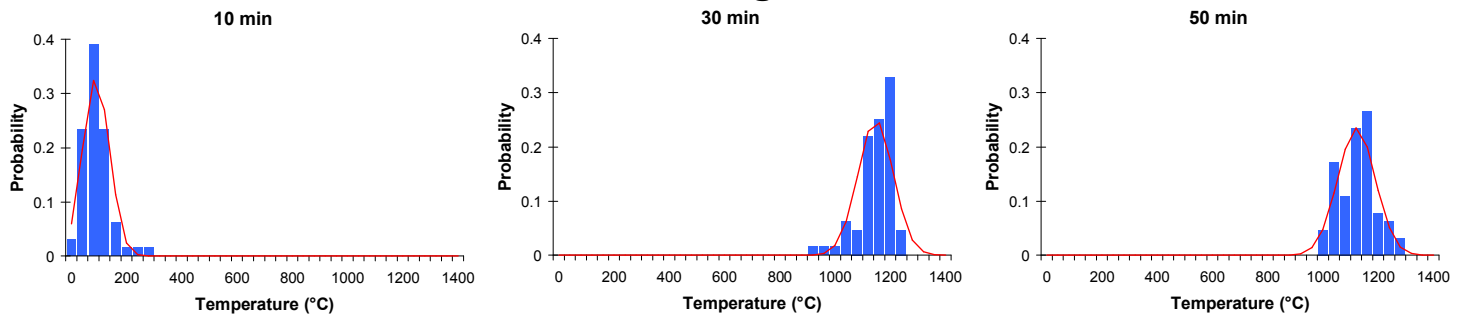

\section{Cardington 7}
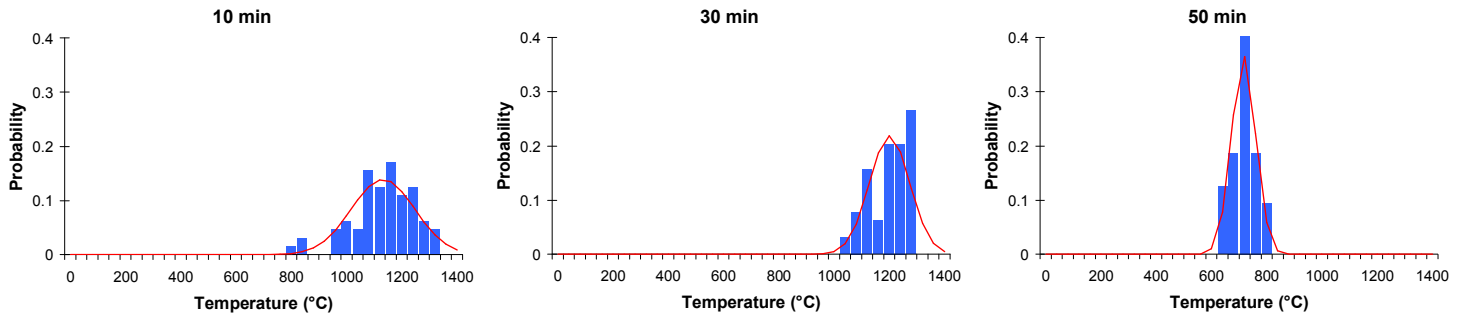

Figure A2: Data distributions with equivalent normal distributions for Cardington Tests with ventilation on opposing sides (Tests 4, 5, 6 and 7). 


\section{APPENDIX B: STRUCTURAL CALCULATIONS}

Simplified heat transfer and structural calculations were used to quantify the effect of the various temperature ranges on each beam type. While it is recognised that these calculations are simplified, when compared to calculating full heat transfer and the subsequent behaviour of the whole structural frame, they are sufficient to provide an insight into the importance of the temperature uniformity assumption being analysed.

\section{B.1 Failure Criterion}

For the purposes of this analysis, structural failure is simply deemed to be a steel temperature of $550^{\circ} \mathrm{C}$. For the unprotected and protected steel beams this is straightforward. For the concrete beam, this criterion is applied to the steel rebar, which is assumed to be the same temperature as the adjacent concrete.

\section{B.2 Unprotected Steel Beam Temperatures}

The unprotected steel beam temperatures were calculated by lumped mass heat transfer, as given by Buchanan [30], and shown below.

$$
\Delta T_{s}=\frac{H_{p}}{A} \frac{1}{\rho_{s} c_{s}}\left[h_{c}\left(T_{g}-T_{s}\right)+\sigma \varepsilon\left(T_{g}^{4}-T_{s}^{4}\right)\right] \Delta t
$$

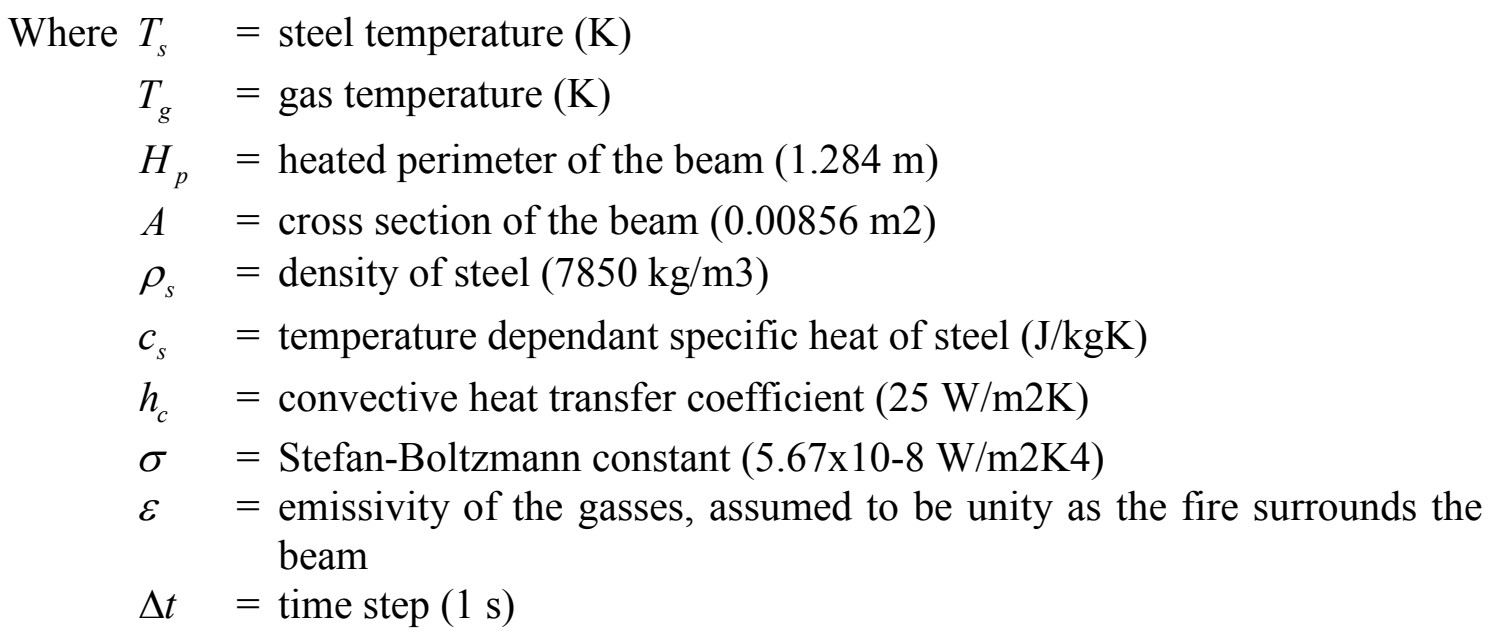

All constants and steel material properties (except the emissivity) are taken from Buchanan, including the temperature dependant specific heat.

\section{B.3 Protected Steel Beam Temperatures}

The protected beam temperature calculation was also taken from Buchanan and is given below. 
$\Delta T_{s}=\frac{H_{p}}{A} \frac{k_{i}}{d_{i} \rho_{s} c_{s}}\left[\frac{\rho_{s} c_{s}}{\left[\rho_{s} c_{s}+\left(H_{p} / A\right) d_{i} \rho_{i} c_{i} / 2\right.}\right]^{\left(T_{g}-T_{s}\right) \Delta t}$

Where $k_{i}=$ thermal conductivity of the insulation $(0.12 \mathrm{~W} / \mathrm{mK})$

$d_{i} \quad=$ thickness of the insulation $(0.012 \mathrm{~m})$

$\rho_{i} \quad=$ density of the insulation $(550 \mathrm{~kg} / \mathrm{m} 3)$

$c_{i} \quad=$ specific heat of the insulation $(1200 \mathrm{~J} / \mathrm{kgK})$

The material properties of the insulation were based on high density perlite, as given by Buchanan. The thickness of the insulation was solved for using Eq. B2, applying the standard temperature-time curve and limiting the steel temperature to below $550^{\circ} \mathrm{C}$ for 60 minutes. This method should ensure a similar level of performance for any insulating material used to a 60 minute fire rating.

\section{B.4 Concrete Beam Temperatures}

To determine the in-depth temperature of the concrete, a one-dimensional finitedifference approach to the heat conduction equation was taken in explicit form, as given by Incropera et al [31]. Their formulation only includes surface convection, so a radiative term was added. This gives Eq. B3 for calculating the surface node temperature and Eq. B4 for the interior nodes.

$$
\begin{aligned}
& T_{0}^{t+1}=\frac{2 \Delta t}{\rho_{c} c_{c} \Delta x}\left[h_{c}\left(T_{g}-T_{0}^{t}\right)+\sigma \varepsilon\left(T_{g}^{4}-T_{0}^{t^{4}}\right)+\frac{k_{c}}{\Delta x}\left(T_{1}^{t}-T_{0}^{t}\right)\right]+T_{0}^{t} \\
& T_{i}^{t+1}=F o\left(T_{i+1}^{t}+T_{i-1}^{t}\right)+\left(1-2 F_{O}\right) T_{i}^{t}
\end{aligned}
$$

Where $T_{i}^{t} \quad=$ the concrete temperature at time $\mathrm{t}$, and location $\mathrm{i}(\mathrm{K})-\mathrm{a}$ subscript of 0 indicates the surface location

$\rho_{c}=$ density of concrete $(2300 \mathrm{~kg} / \mathrm{m} 3)$

$c_{c}=$ specific heat of concrete $(1000 \mathrm{~J} / \mathrm{kgK})$

$k_{c}=$ thermal conductivity of concrete $(1.3 \mathrm{~W} / \mathrm{mK})$

$\Delta t \quad=$ time step $(0.5 \mathrm{~s})$

$\Delta x=$ element length $(0.001 \mathrm{~m})$

$F o=$ Fourier number (-), given in Eq. A5

$F o=\frac{k_{c} \Delta t}{\rho_{c} c_{c} \Delta x^{2}}$

The time step and element length were selected to meet the stability criteria highlighted by Incropera et al. The concrete material properties were taken from Buchanan for calcareous concrete. 
J. Stern-Gottfried, G. Rein, L. A. Bisby, J. L. Torero. Experimental review of the homogeneous temperature assumption in post-flashover compartment fires, Fire Safety Journal 2010; 45:249. doi: $10.1016 / j$.firesaf.2010.03.007. Open access version at http://www.era.lib.ed.ac.uk/handle/1842/1152

The calculation method was implemented to find the concrete temperature 30 $\mathrm{mm}$ from the surface, as this was the cover depth to the rebar used. It is assumed that the rebar temperature is the same as the adjacent concrete temperature. 